Article

\title{
The Aryl Hydrocarbon Receptor (AhR) Mediates the Counter-Regulatory Effects of Pelargonidins in Models of Inflammation and Metabolic Dysfunctions
}

\author{
Michele Biagioli ${ }^{1}$, Adriana Carino ${ }^{1}$, Chiara Fiorucci ${ }^{1}$, Giannamaria Annunziato ${ }^{2}$ (D), \\ Silvia Marchianò ${ }^{1}$, Martina Bordoni ${ }^{1}$, Rosalinda Roselli ${ }^{3}$, Cristina Di Giorgio ${ }^{1}$, \\ Federica Castiglione ${ }^{1}$, Patrizia Ricci ${ }^{1}$, Agostino Bruno ${ }^{2}$, Andrea Faccini ${ }^{4}$, Eleonora Distrutti ${ }^{5}$, \\ Monia Baldoni ${ }^{1}$, Gabriele Costantino ${ }^{2}$ and Stefano Fiorucci ${ }^{1, *(D)}$ \\ 1 Dipartimento di Scienze Biomediche e Chirurgiche, Università di Perugia, 06100 Perugia, Italy \\ 2 Department of Food and Drugs, University of Parma, 43100 Parma, Italy \\ 3 Department of Pharmacy, University of Naples Federico II, 80100 Naples, Italy \\ 4 Centro Interdipartimentale Misure ‘G. Casnati'—University of Parma, 43100 Parma, Italy \\ 5 Azienda Ospedaliera di Perugia, 06100 Perugia, Italy \\ * Correspondence: stefano.fiorucci@unipg.it
}

Received: 25 June 2019; Accepted: 5 August 2019; Published: 7 August 2019

\begin{abstract}
Pelargonidins are anthocyanidins thought to be beneficial for the human health, although controversies exist over the doses needed and the unclear mechanism of action, along with poor systemic bioavailability. One putative target of pelargonidins is the aryl hydrocarbon receptor (AhR). A synthetic pelargonidin (Mt-P) was synthesized by the methylation of the pelargonidin (the natural compound indicated as P). Mt-P transactivated the AhR with an $\mathrm{EC}_{50}$ of $1.97 \mu \mathrm{M}$ and was $\sim 2$-fold more potent than the natural compound. In vitro Mt-P attenuated pro-inflammatory activities of Raw264.7 macrophage cells in an AhR-dependent manner. In vivo, administration of the Mt-P in $\mathrm{Balb} / \mathrm{c}$ mice resulted in a dose-dependent attenuation of signs and symptoms of colitis induced by TNBS. A dose of $5 \mathrm{mg} / \mathrm{kg}$ Mt-P, but not the natural compound P, reversed intestinal inflammation and increased expression of Tnf- $\alpha$, Ifn- $Y$, and Il- 6 , while promoted the expansion of regulatory T cells and M2 macrophages. In C57BL/6J mice fed a high fat diet (HFD), Mt-P attenuated body weight gain, intestinal and liver inflammation, and ameliorated insulin sensitivity, while worsened liver steatosis by up-regulating the liver expression of $\mathrm{Cd} 36$ and Apo100b. These effects were abrogated by AhR gene ablation. Mt-P is a synthetic pelargonidin endowed with robust AhR agonist activity that exerts beneficial effects in murine models of inflammation and metabolic dysfunction.
\end{abstract}

Keywords: pelargonidins; aryl hydrocarbon receptor; colitis; hepatic steatosis; inflammation

\section{Introduction}

The aryl hydrocarbon receptor (AhR) is a ligand-activated nuclear receptor that belongs to the basic helix-loop-helix (bHLH)/PerARNT-Sim (PAS) superfamily. Although AhR was originally described as a xenobiotics sensor, it is now well established that dietary/intestinal microbiota metabolites such as kynurenines represent the physiological ligands [1]. Similarly to other nuclear receptors, in the absence of a ligand, AhR resides in cytoplasm as a component of a chaperone complex that includes a dimer of heat shock protein 90 (Hsp90), together with the cochaperones such as p23, AhR interacting protein (AIP), and the immunophilin-like AH receptor-interacting protein that binds to and inactivates the receptor [2]. This multiprotein complex is released upon agonist ligation, allowing the receptor to translocate to the nucleus to form a heterodimeric complex with the AhR nuclear translocator 
(ARNT). The AhR/ARNT dimer is then recruited to the promoter of AhR target genes, where it binds to a consensus sequence known as dioxin or xenobiotic response elements (XREs), allowing the transcription of a large family of AhR-dependent proteins including xenobiotic metabolizing enzymes [3].

The AhR is widely expressed by cells of innate/adaptive immunity [4]. In the gastrointestinal tract, several immune cell subsets-including T helper (Th) 17 cells, IL-22 secreting group 3 innate lymphoid cells (ILC3s), and regulatory T cells (Treg) - express the receptor, providing a network of regulatory signals essential for development and maintenance of immune tolerance $[5,6]$. Accordingly, not only is AhR gene expression negatively regulated in patients with inflammatory bowel disease (IBD) [7], but AhR ligands have been proven effective in attenuating inflammation and immune dysfunction in murine models of colitis, while $\mathrm{AhR}^{-/-}$mice are more prone than their wild-type counterparts to develop severe immune dysfunction [8-11].

In addition to immune cells, high levels of AhR are detected in intestinal epithelial cells and the receptor appears essential for the maintenance of the intestinal barrier integrity [1]. Since a compromised integrity of the intestinal barrier has substantial implications for human health even beyond the intestine, AhR has emerged as potential target in the treatment of highly prevalent human disorders.

Chronic exposure to a high caloric intake resulting in metabolic syndrome, diabetes, and obesity compromises the integrity of intestinal barrier function, promoting leakage of bacterial products, a state of subclinical inflammation, and accumulation of inflammatory mediators in metabolic tissues such as the white adipose tissue (WAT) and liver [12,13]. Accordingly, changes in intestinal barrier function, promoted by dysbiotic intestinal microbiota and/or genetic and dietetic factors, promote transition from the simple steatosis to steato-hepatitis, representing a validated target in the treatment of non-alcoholic steato-hepatitis (NASH), a highly prevalent human disease for which therapy is still sub-optimal [14].

Anthocyanins are a subgroup of flavonoids derived from the respective aglycons (anthocyanidins), from which they are differentiated by the addition of a glycosidic group $[15,16]$. Pelargonidin is a water soluble anthocyanidin responsible for the red/orange colors of berries such as ripe raspberries and strawberries, as well as blueberries, blackberries, cranberries, but also saskatoon berries and chokeberries too. It is also found in plums and pomegranates, confers red radishes their color, and occurs in nature as glycosylated derivatives [17]. While, similarly to other anthocyanins, pelargonidin is thought to be beneficial for human health [18-20], controversies exist over the doses needed to reach these effects, along with poor systemic bioavailability and unclear mechanism(s) of action.

In the present study, we report the generation and pharmacological characterization of a synthetic pelargonidin, obtained by de novo synthesis, endowed with robust AhR agonist activity. By using pharmacological and genetic approaches, we demonstrate that the novel derivative activates the AhR in the intestine and metabolic tissues, and is beneficial in reducing inflammation in murine models of intestinal inflammation and NASH.

\section{Materials and Methods}

\subsection{Chemistry}

All reagents were purchased from Sigma-Aldrich (St. Louis, MO, USA), Alfa Aesar (Haverhill, MA, USA) and Enamine (Monmouth Jct, NJ, USA) at reagent purity and, unless otherwise noted, used without any further purification. Dry solvents used in the reactions were obtained by distillation of technical grade materials over appropriate dehydrating agents. Reactions were monitored by thin layer chromatography on silica gel-coated aluminum foils (silica gel on Al foils, SUPELCO Analytical, Sigma-Aldrich) at 254 and $365 \mathrm{~nm}$. Where indicated, intermediates and final products were purified by silica gel flash chromatography (silica gel, $\mathrm{C} 18$ reverse phase), using appropriate solvent mixtures. ${ }^{1} \mathrm{H}$ NMR and ${ }^{13} \mathrm{C}$ NMR spectra were recorded on a BRUKER AVANCE spectrometer at 400 and $100 \mathrm{MHz}$, 
respectively, with TMS as internal standard. All compounds were tested at purity of 95\% or higher (by HPLC/MS).

\subsection{Extraction and Hydrolysis of Natural Pelargonidins}

The edible red radish (European variety) $(1 \mathrm{~kg})$ was purchased from a local supermarket, Parma, Italy. It was stored at $4{ }^{\circ} \mathrm{C}$ and washed thoroughly prior to use. Washed red radish was peeled into small pieces prior to solvent extraction. Pelargonidins were extracted by stirring $5 \mathrm{~g}$ of finely-cut peel with $20 \mathrm{~mL}$ of methanol for $18 \mathrm{~h}$ at room temperature. The extract was then filtered on a paper filter. After filtration on a $0.2 \mu \mathrm{m}$ PTFE filter, the extract was purified by silica gel in reverse phase starting from $\mathrm{H}_{2} \mathrm{O} / \mathrm{MeOH} / \mathrm{HCOOH}$ (9:1:0.01) to $\mathrm{MeOH} \mathrm{100 \% ,} \mathrm{and} \mathrm{the} \mathrm{anthocyanins} \mathrm{fraction} \mathrm{was} \mathrm{collected} \mathrm{and}$ dried under $\mathrm{N}_{2}$ flux. The pelargonidins purified extract $(300 \mathrm{mg})$ was dissolved in $\mathrm{HCl} 1 \mathrm{~N}(10 \mathrm{~mL})$ and allowed to react at $100{ }^{\circ} \mathrm{C}$ for $3 \mathrm{~h}$. After filtration on a $0.2 \mu \mathrm{m}$ PTFE filter, the reaction mixture was dried under $\mathrm{N}_{2}$ flux and purified by silica gel on reverse phase, starting from $\mathrm{H}_{2} \mathrm{O} / \mathrm{MeOH} / \mathrm{HCOOH}$ (9:1:0.01) to $\mathrm{MeOH} \mathrm{100 \% ,} \mathrm{and} \mathrm{the} \mathrm{pelargonidins} \mathrm{fraction} \mathrm{collected} \mathrm{and} \mathrm{dried} \mathrm{under} \mathrm{N}_{2}$ flux [21]. HRMS (ESI) calculated for $\mathrm{C}_{15} \mathrm{H}_{11} \mathrm{O}_{5}\left([\mathrm{M}+\mathrm{H}]^{+}\right)$272.0606; found 272.0600.

\subsection{Synthesis of Methylated Pelargonidin}

For the synthesis of methylated pelargonidin (Mt-P), the starting materials 2 and 3 were commercially available. Compounds 2 (350 mg, $1 \mathrm{eq}$ ) and 3 (336 mg, $1.1 \mathrm{eq}$ ) were dissolved in $\mathrm{AcOEt} / \mathrm{MeOH}(1: 2.5 \mathrm{~mL})$ and gaseous $\mathrm{HCl}$ was bubbled for $1 \mathrm{~h}$ in the mixture at room temperature. The solution became dark red. After $1 \mathrm{~h}$, the reaction was allowed to react at room temperature overnight. After this period $\mathrm{Et}_{2} \mathrm{O}$ was added to the reaction mixture; after $40 \mathrm{~min}$, the crude was filtered by a Buckner funnel and the red powder collected and triturated with $\mathrm{Et}_{2} \mathrm{O}$ with $0.1 \%$ of formic acid. Finally, the product was filtered with a Buckner funnel and collected (Scheme 1) [22].

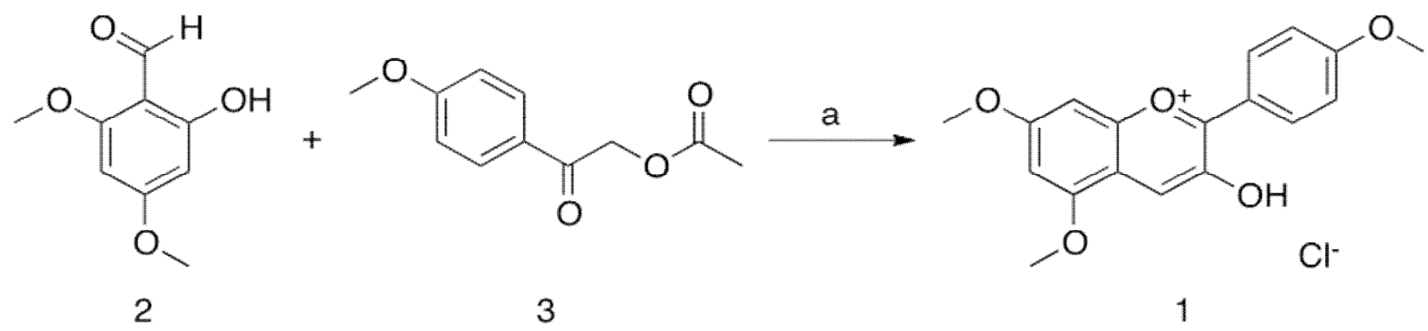

Scheme 1. Methylated pelargonidin (Mt-P) synthesis.

Purified by filtration and washed with Et2O. Yield: 33\% (brown-red powder); ${ }^{1} \mathrm{H}-\mathrm{NMR}$ (DMSO $300 \mathrm{MHz}): \delta 2.74(\mathrm{~s}, 3 \mathrm{H}), 3.01(\mathrm{~s}, 3 \mathrm{H}), 3.84(\mathrm{~s}, 3 \mathrm{H}), 6.69(\mathrm{~s}, 1 \mathrm{H}), 6.91(\mathrm{~s}, 1 \mathrm{H}), 7.18(\mathrm{~d}, J=9.25,2 \mathrm{H}), 8.60$ $(\mathrm{d}, J=9.25,2 \mathrm{H}), 8.55(\mathrm{~s}, 1 \mathrm{H}), 13.02(\mathrm{~s}, 1 \mathrm{H})$. HRMS (ESI) calculated for $\mathrm{C}_{18} \mathrm{H}_{17} \mathrm{O}_{5}\left([\mathrm{M}+\mathrm{H}]^{+}\right)$314.3246; found 314.3200 .

\subsection{LC-HRMS Analyses}

Liquid Chromatography-High Resolution Mass (LC-HRMS) analyses were carried out on a DIONEX Ultimate3000 Thermo Fisher Scientific equipped with a Ultimate300 Variable Wavelength Detector and a LTQ Orbitrap XL (Thermo Fisher Scientific; Waltham, MA, USA). Electrospray ionization at positive ion modes was performed with a spray voltage $3 \mathrm{kV}$; capillary voltage $13 \mathrm{~V}$; source temperature $275^{\circ} \mathrm{C}$; tube lens $80 \mathrm{~V}$; sheath gas flow rate 20; aux gas flow rate 5; and sweep gas flow rate 5 . The mass data acquisition was performed by two scan event: Scan event 1, FTMS $+p$ res $=30,000 \mathrm{o}$ (200-1500); scan event 2, FTMS + $p$ res $=30,000$ o (200-1500) SID $=35$ V.

Samples were injected on an Aeris Peptide 3.6u XB-C18 $2.1 \mathrm{~mm} \times 15 \mathrm{~cm}$ (Phenomenex) The mobile phase consisted of water with $0.1 \%$ formic acid (solvent $\mathrm{A}$ ) and methanol with $0.1 \%$ formic acid (solvent B). Gradient: 0-5 min 95\% A; 5-45 min from 95\% A to 5\% A; 45-51 min 5\% A; 51-52 from 
$5 \%$ to $95 \%$ A; $52-6095 \%$ A. Flow rate was $0.2 \mathrm{ml} / \mathrm{min}$. UV/Vis analyzer wavelength: $280 \mathrm{~nm}, 440 \mathrm{~nm}$, $508 \mathrm{~nm}, 522 \mathrm{~nm}$. Column temperature $40{ }^{\circ} \mathrm{C}$.

\subsection{Homology Model of the PAS B Domain of hAhR and Docking Studies}

The X-ray crystal structure of the Hypoxia Inducing Factor (HIF)-1 $\alpha$ PasB domain (pdb code 4H6J) was used as template to generate the 3D model structure of the AhR PAS B domain. Twenty 3D models were generated using Modeller software. The obtained models were scored using the available scoring functions in Modeller 9 software (DOPE score) and through visual inspections [23]. The protonation state of ionizable residues was fixed by using the Protein Preparation Wizard of the Maestro graphical user interface and then checked by visual inspection. The geometry of the final model was optimized using several cycles of OPLS3 force field (available in Maestro) minimization, until a gradient of $0.001 \mathrm{kcal} /\left(\mathrm{mol} \cdot \AA^{2}\right)$ was reached. The structure thus obtained was used to perform docking studies by using Glide. The 3D structure of the ligand was built using the fragment builder tool of Maestro. The compound was geometrically optimized by means of Macromodel, using MMFFs as force field and water as implicit solvent until a convergence value of $0.05 \mathrm{kcal} /\left(\mathrm{mol} \cdot \AA^{2}\right)$. The computational protocol applied consists of the application of 500 steps of the Polak-Ribiere conjugate gradient (PRCG) for structure minimizations. The grid was centered on the His291 and Ser365 residues. Each docking run was carried out with the standard precision (SP) method, and the van der Waals scaling factor of nonpolar atoms was set to 0.8 . Twenty docking poses were obtained, and among these poses we selected the best pose in accordance to (i) the Glide scoring function and that (ii) able to interact at the same time with His 291 and Ser365 residues. The selected docking pose was minimized using OPLS3 as force field and the PRCG method until a gradient of $0.001 \mathrm{kcal} /\left(\mathrm{mol} \cdot \AA^{2}\right)$ was obtained, applying a stepwise relaxation protocol for which harmonic constraints were progressively reduced for backbone, side chains, and ligand atoms.

\subsection{Cell Culture}

HepG2 cells, a human liver cancer cell line from ATCC (Manassas, VA, USA), were cultured at $37{ }^{\circ} \mathrm{C}$ in E-MEM supplemented with $10 \%$ FBS, $1 \%$ glutamine, and $1 \%$ penicillin/streptomycin. RAW264.7 cells, a murine macrophage cell line, were from ATCC (Manassas, VA, USA); EL4 cells, a murine T lymphocyte cell line, were from ATCC (Manassas, VA, USA); Caco-2 cells, a human intestinal epithelial cell line, were from Sigma-Aldrich (Saint Louis, MI, USA). Raw264.7, EL4, and Caco-2 cells were grown at $37^{\circ} \mathrm{C}$ in D-MEM containing $10 \% \mathrm{FBS}, 1 \% \mathrm{~L}$-glutamine, and $1 \%$ penicillin/streptomycin. Cells were regularly passaged to maintain exponential growth. RAW264.7, EL4, and Caco-2 cells were classically activated with LPS (5 ng/mL, Sigma-Aldrich L2880) + IFN- $\gamma(20 \mathrm{ng} / \mathrm{mL}$, eBioscience, San Diego, CA, USA) for $16 \mathrm{~h}$ alone or in combination with P or Mt-P $(0.1,1,10$, and $20 \mu \mathrm{M})$ for the analysis of expression of several genes.

\subsection{Transactivation Assay}

For AhR-mediated transactivation, HepG2 cells were plated at $5 \times 10^{4}$ cells/well in a 24-well plate. Cells were transfected with $200 \mathrm{ng}$ of the reporter vector pLightAhRE, $100 \mathrm{ng}$ of pCMVXL4AhR, and $100 \mathrm{ng}$ of pGL4.70 (Promega, Madison, WI, USA), a vector encoding the human Renilla luciferase gene. To evaluate FXR-mediated transactivation, HepG2 cells were transfected with $100 \mathrm{ng}$ of human pSG5-FXR, 100 ng of human pSG5-RXR, 200 ng of the reporter vector $\mathrm{p}(\mathrm{hsp} 27)-\mathrm{TK}-\mathrm{LUC}$ containing the FXR response element IR1 cloned from the promoter of heat shock protein 27 (hsp27), and with $100 \mathrm{ng}$ of pGL4.70 Renilla. To investigate the specificity of these compounds versus PXR, HepG2 cells were transfected with 100 ng pSG5-PXR, 100 ng pSG5-RXR, 100 ng pGL4.70 Renilla, and $200 \mathrm{ng}$ reporter vector containing the PXR target gene promoter (CYP3A4 gene promoter) cloned upstream of the luciferase gene (pCYP3A4promoter-TKLuc). To evaluate LXR $\alpha$-mediated transactivation, HepG2 cells were transfected with $20 \mathrm{ng}$ of the reporter vector $\mathrm{p}(\mathrm{UAS}) 5 \mathrm{XTKLuc}, 100 \mathrm{ng}$ of a vector containing the ligand binding domain of $L X R \alpha$ cloned upstream of the GAL4-DNA binding 
domain (i.e., pSG5-LXR $\alpha$ LBD-GAL4DBD), and 100 of pGL4.70 (Promega, Madison, WI, USA), a vector encoding the human Renilla gene. To evaluate GPBAR1-mediated transactivation, HEK-293T cells were transfected with 200 ng of human pGL4.29 (Promega, Madison, WI, USA), a reporter vector containing a cAMP response element (CRE) that drives the transcription of the luciferase reporter gene luc2P, with $100 \mathrm{ng}$ of pCMVS.PORT6-human GPBAR1, and with $100 \mathrm{ng}$ of pGL4.70 Renilla. At $24 \mathrm{~h}$ post-transfection, cells were stimulated $18 \mathrm{~h}$ with $5 \mathrm{nM}$ TCDD, $10 \mu \mathrm{M}$ CDCA, $500 \mathrm{nM}$ Rifaximin, $10 \mu \mathrm{M}$ GW3965, or $10 \mu \mathrm{M}$ TLCA, and both pelargonidin and methylated pelargonidin (10 and $50 \mu \mathrm{M})$. Luciferase activities were assayed and normalized with Renilla activities. Dose-response curves were performed in HepG2 cells transfected with AhR, as described above, and then treated with increasing concentrations of both pelargonidin and methylated pelargonidin $(1,5,10,25$, and $50 \mu \mathrm{M})$. At $18 \mathrm{~h}$ post-stimulation, cellular lysates were assayed for luciferase and Renilla activities using the Dual-Luciferase Reporter assay system (E1980, Promega, Madison, WI, USA). Luminescence was measured using Glomax 20/20 luminometer (Promega, Madison, WI, USA). Luciferase activities (RLU) were normalized with Renilla activities (RRU).

\subsection{Wound-Healing Assay}

To evaluate the intestinal mucosal healing, we used a classic in vitro wound healing assay, which consists in creating a "scratch" in a cell monolayer. Caco- 2 cells were grown to confluence ( 3 days) on 12-well culture plates $\left(1 \times 10^{5}\right.$ cells/well) and then starved overnight in $0.5 \%$ FBS containing medium. The cell monolayers were scraped in a straight line using a p200 sterile pipette tip in order to create a "scratch"; cell debris were removed by washing with PBS. The cells were then incubated with $2 \mathrm{~mL}$ of $0.5 \%$ FBS containing medium with or without LPS $(1 \mu \mathrm{g} / \mathrm{Ml})$ alone or in combination with P or Mt-P $(20 \mu \mathrm{M})$. Cells treated only with the vehicle (NT) or only with TGF $\beta(5 \mathrm{ng} / \mathrm{mL})$ were used as negative and positive control wells. To measure the migratory response of the cells into the scrape wounds, microscopic photographs were taken at $0 \mathrm{~h}$ and $24 \mathrm{~h}$ with a digital camera on an inverted microscope at $10 \times$ magnification. Images were analyzed by NIH ImageJ software (NIH, Bethesda, MD, USA) to calculate the area of scratch wound and represented as \% of wound healed relative to the control wells (that was arbitrarily assigned as $100 \%$ ).

\subsection{Chromatin Immunoprecipitation (ChIP)}

For ChIP assay, we studied the promoter of the murine gene encoding for the CYP1a1, investigating the sequence for the binding of AhR/ARNT dimer. RAW264.7 cells were exposed or not to LPS with P or Mt-P for $16 \mathrm{~h}$ and then crosslinked with formaldehyde. Chromatin immunoprecipitation (ChIP) assays were performed according the manufactured protocols (EZ-ChIPTM Upstate, \#17-371, Millipore, Burlington, MA, USA). Briefly, cell extracts were sonicated and divided. Antibodies $(5 \mu \mathrm{g})$ against $\mathrm{AhR}$ and normal goat IgG were added for immunoprecipitation. The immune-precipitated chromatin was recovered and purified. The CYP1a1 promoter DNA was quantified by rtPCR analysis using primers around the binding site in the proximal promoter of CYP1a1 (for GTGCAGATACCTCCCAGACC; rev AAGCAGTCCCTTCATGTGCT). Primers spanning a region located at $\sim 14,000 \mathrm{~kb}$ downstream of the CYP1a1 transcriptional start site (ACACAGCCCATTAGGATTCG; rev TGGGGAAAGAGGACACGTAG) were used as control. At least three replicates of each group were performed.

\subsection{Animals}

Balb/c mice were purchased from Charles River (Wilmington, MA, USA). AhR null mice on C57BL/6 background and C57BL/6 congenic littermates were originally purchased from Charles River (Wilmington, MA, USA). The colonies were maintained in the animal facility of University of Perugia. Mice were housed under controlled temperatures $\left(22^{\circ} \mathrm{C}\right)$ and photoperiods (12:12-h light/dark cycle), allowed unrestricted access to standard mouse chow and tap water, and allowed to acclimatize to these conditions for at least 5 days before inclusion in an experiment. The study was conducted in 
agreement with the Italian law and the protocol was approved by an ethical committee of University of Perugia and by a National Committee of Italian Ministry of Health permits $n^{\circ} 1126 / 2016-P R$ and $n$. 583/2017-PR. The health and body conditions of the animals were monitored daily by the Veterinarian in the animal facility.

\subsection{Purification of Macrophages from the Spleen}

The spleens were taken from $\mathrm{AhR}^{+/+}$and $\mathrm{AhR}^{-/-}$mice under sterile conditions. After homogenization, we performed the lysis of the red blood cells by hypotonic lysis. The cell pellet was resuspended in RPMI with $1 \%$ glutamine, $1 \%$ PS, and $20 \%$ of FBS at the concentration of $10^{7} / \mathrm{mL}$. Macrophages were recovered by adherence to plastic after incubation for $2 \mathrm{~h}$ at $37^{\circ} \mathrm{C}$ and $5 \%$ of $\mathrm{CO}_{2}$. The recovered macrophage-enriched cells were classically activated with LPS ( $5 \mathrm{ng} / \mathrm{mL}$, Sigma-Aldrich L2880) + IFN- $\gamma(20 \mathrm{ng} / \mathrm{mL}$, eBioscience, San Diego, CA, USA) for $16 \mathrm{~h}$ alone or in combination with $\mathrm{P}$ $(20 \mu \mathrm{M})$ or Mt-P $(20 \mu \mathrm{M})$ for the analysis of expression of several genes.

\subsection{Mice Model of Intestinal Inflammation}

To investigate the effects of the two pelargonidins in a mouse model of intestinal inflammation, 8-10 weeks old male mice on a Balb/c and C57BL/6J (AhR wild type and $\mathrm{AhR}^{-/-}$congenic littermates) genetic background were used. Mice were injected intrarectally with trinitrobenzenesulfonic acid (TNBS) (Sigma Chemical Co., St. Louis, MO, USA), as described elsewhere [24]. In brief, in TNBS-colitis model mice were fasted for $12 \mathrm{~h}$ overnight (day -1). The day after (day 0 ), under profound sedation induced by administration of mixture of tiletamine hypochoride and zolazepam hypocloride/xylazine at a dose of $50 / 5 \mathrm{mg} / \mathrm{Kg}$, a $3.5 \mathrm{~F}=11.55 \mathrm{~mm}$ catheter was inserted into the colon up to $4 \mathrm{~cm}$ from the anus and $1 \mathrm{mg}$ of TNBS in 50\% ethanol administered via the catheter into the colon lumen using a $1 \mathrm{~mL}$ syringe (injection volume of $100 \mu \mathrm{L}$ ). Control mice received $50 \%$ ethanol alone. At the end of the experiment, 4 days after the administration of TNBS, surviving mice were sacrificed, blood samples collected by cardiac puncture, and the colon excised, weighed, and evaluated for macroscopic damage. According to the experimental design, mice were administered orally pelargonidin $(\mathrm{P})$ or $\mathrm{Mt}-\mathrm{P}$ from 1 to $10 \mathrm{mg} / \mathrm{kg} /$ day, or dexamethasone, $5 \mathrm{mg} / \mathrm{kg} /$ day, by intraperitoneal injection (i.p.). The severity of colitis was scored daily in each mouse by assessing body weight, the fecal occult blood, and stool consistency. Each parameter was scored from 0 to 4 and the sum represents the Colitis Disease Activity Index (CDAI). The scoring system was as follows: Percent of body weight loss: None $=0 ; 1-5 \%=1$; $5-10 \%=2 ; 10-20 \%=3 ;>20 \%=4$. Stool consistency: Normal = 0; soft but still formed $=1$; very soft $=2$; diarrhea $=3$; liquid stools that stick to the anus or anal occlusion $=4$. Fecal blood: None $=0$; visible in the stool = 2; severe bleeding with fresh blood around the anus and very present in the stool $=4$.

\subsection{Measurement of Intestinal Permeability}

Two days before the sacrifice, a permeability test was carried out using a fluorescein isothiocyanate conjugated dextran (FITC-dextran) (Sigma-Aldrich, St. Louis, MO, USA, catalog number: FD4). FITC-dextran was dissolved in PBS at a concentration of $100 \mathrm{mg} / \mathrm{mL}$ and administered to each mouse at the dose of $44 \mathrm{mg} / 100 \mathrm{~g}$ body weight by oral gavage. After $4 \mathrm{~h}$, mice were anesthetized by isoflurane inhalation and blood collected from the facial vein [25].

\subsection{Isolation and Flow Cytometry Analysis of Colon Lamina Propria Cells}

The cells were isolated from the colon lamina propria using the Lamina Propria Dissociation Kit (Miltenyi Biotec, Bergisch Gladbach, Germany; 130-097-401), according to the instructions.

Flow cytometry analyses were carried out using a two-laser standard configuration BD FACSVia ${ }^{\mathrm{TM}}$ flow cytometry system. Data were analyzed using FlowJo software (TreeStar). The gates were set using the fluorescence minus one (FMO) control strategy. FMO controls are samples that include all conjugated Abs present in the test samples except one. The channel in which the conjugated $\mathrm{Ab}$ is missing is the one for which the FMO provides a gating control. The following mAbs were used: 
CD4 PerCp-Cy5.5 (RM4-5, eBioscience, Affymetrix Santa Clara, CA, USA); CD11b Pe-Cy7 (M1/70, eBioscience, Affymetrix, Santa Clara, CA, USA); Gr1 PE (RB6-8C5, BioLegend, San Diego, CA, USA); IL-10 FITC (JES5-16E3, eBioscience, Affymetrix Santa Clara, CA, USA); and FoxP3 APC (FJK-16s, eBioscience, Affymetrix, Santa Clara, CA, USA).

\subsection{NASH Model}

In another experimental setting, $\mathrm{Ahr}^{-/-}$male mice on a C57BL6/Sj background and their congenic littermates $\left(\mathrm{AhR}^{+/+}\right.$) were fed a high fat diet (HFD) containing $59 \mathrm{KJ} \%$ fat plus $1 \%$ cholesterol, w/o sugar (ssniff ${ }^{\circledR}$ EF R/M acc. D12330 mod. $22.7 \mathrm{ME} / \mathrm{Kg}$ ) and fructose (HFD-F) in drinking water (42 g/L) or normal chow diet (5 and 7 mice, respectively) [26]. After 7 days, WT and $\mathrm{Ahr}^{-/-}$HFD-F mice were randomized to receive HFD-F alone ( 6 and 8 mice, respectively) or in combination with Mt-P $(5 \mathrm{mg} / \mathrm{Kg} / \mathrm{die})$ ( 6 and 9 mice, respectively) by gavage for 7 weeks. Mice were housed under controlled temperature $\left(22^{\circ} \mathrm{C}\right)$ and photoperiods (12:12-h light/dark cycle), and allowed unrestricted access to standard mouse chow and tap water. The experimental protocols were approved by the Animal Care and Use Committee of the University of Perugia and by the Italian Minister of Health and Istituto Superiore di Sanità (Italy), and were in agreement with the European guidelines for use of experimental animals (permission n. 1126/2016-PR and n. 583/2017-PR, respectively). The health and body conditions of the animals were monitored daily by the Veterinarian in the animal facility. On the day of sacrifice, fed mice were deeply anesthetized with a mixture of tiletamine hypochoride and zolazepam hypocloride/xylazine at a dose of $50 / 5 \mathrm{mg} / \mathrm{Kg}$ and sacrificed before 12 a.m. At the end of the study, the abdominal circumference (AC) (immediately anterior to the forefoot), body weight, and body length (nose-to-anus or nose-anus length) were measured in anesthetized mice at time of sacrifice. The body weight and body length were used to calculate the body mass index (BMI) (=body weight $(\mathrm{g}) /$ length $\left.^{2}\left(\mathrm{~cm}^{2}\right)\right)$.

\subsection{Biochemical Analyses, oral glucose tolerance test (OGTT), and Bile Acid Assay}

Glucose, cholesterol, triglycerides, high density lipoproteins (HDLs), and low density lipoproteins (LDLs) plasmatic levels were quantified using an automated clinical chemistry analyzer (Cobas, Roche Basel, Switzerland). After 7 weeks of HFD-F, mice were fasted overnight and orally administered glucose ( $1.5 \mathrm{~g} / \mathrm{kg}$ body weight) for OGTT. The blood glucose concentrations were measured at $0,15,30$, 60, 90, and $120 \mathrm{~min}$ after feeding or injection using a portable glucose meter (Accu-Check Go, Roche, Basel, Switzerland) [27]. Gallbladder bile acids were quantified by a liquid chromatography-tandem mass spectrometry (MS/MS) analysis, as described elsewhere [28]. Briefly, the stock solutions of the individual tauro-conjugated and un-conjugated bile acids were prepared separately in methanol at a concentration of $1 \mathrm{mg} / \mathrm{mL}$. All stock solutions were stored at $-20^{\circ} \mathrm{C}$. Calibration standards were prepared by combining appropriate volumes of each bile acid stock solution and methanol. The calibration range was from $10 \mathrm{nM}$ to $100 \mu \mathrm{M}$ of each bile acid in the final solution. $10 \mathrm{mg}$ of lyophilized gallbladder samples were manually pestled using a mortar and dissolved in $1 \mathrm{~mL} \mathrm{CH3OH}$. After centrifugation at $16,000 \times g$ for $10 \mathrm{~min}, 500 \mu \mathrm{L}$ of supernatants were lyophilized and reconstituted in $100 \mu \mathrm{L}$ of $40 \%$ water: $60 \% \mathrm{MeOH}$ with $0.1 \%$ formic acid and ammonium acetate $5 \mathrm{mM}$. A bile acid extraction yield of $95 \%$ has been measured using bile acids standards addition in gallbladder samples before and after the deproteinization procedure [26].

\subsection{Histology}

For histological examination, samples of distal colon ( $2-3 \mathrm{~cm}$ from the anus), portions of the right and left liver lobes, and epididymal adipose tissue were fixed in 10\% formalin, embedded in paraffin, sectioned, and stained with Sirius red and/or Hematoxylin/Eosin (H\&E) for morphometric analysis. NASH severity (steatosis, hepatocytes ballooning, lobular inflammation, and portal inflammation) was scored in H\&E-stained cross sections using an adapted grading system of human NASH, as described 
previously [29]. Hepatic fibrosis score was evaluated in Sirius red stained sections, as described previously [30].

\subsection{Reverse Transcription of $m R N A$ and Real-Time PCR}

RNA was extracted from the liver, colon, spleen, epididymal adipose tissue (eWAT), and brown adipose tissue (BAT) using TRIzol reagent (Invitrogen) and Direct-zol ${ }^{\mathrm{TM}}$ RNA MiniPrep w/Zymo-Spin ${ }^{\mathrm{TM}}$ IIC Columns (Zymo Research, Irvine, CA, USA). After purification from genomic DNA using DNase I (Thermo Fisher Scientific, Waltham, MA, USA), $1 \mu \mathrm{g}$ of RNA from each sample was reverse transcribed using random hexamer primers with SuperScript II (Thermo Fisher Scientific, Waltham, MA, USA) in a $20-\mu \mathrm{L}$ reaction volume; $10 \mathrm{ng}$ of cDNA was amplified in a $20-\mu \mathrm{L}$ solution containing $200 \mathrm{nM}$ of each primer and $10 \mu \mathrm{L}$ of SYBR Select Master Mix (Thermo Fisher Scientific, Waltham, MA, USA). All reactions were performed in triplicate using the following thermal cycling conditions: $3 \mathrm{~min}$ at $95{ }^{\circ} \mathrm{C}$, followed by 40 cycles of $95{ }^{\circ} \mathrm{C}$ for $15 \mathrm{~s}, 56{ }^{\circ} \mathrm{C}$ for $20 \mathrm{~s}$, and $72{ }^{\circ} \mathrm{C}$ for $30 \mathrm{~s}$, using a StepOnePlus system (Applied Biosystems, Foster City, CA, USA). The relative mRNA expression was calculated according to the $\Delta \mathrm{Ct}$ method. Primers were designed using the software PRIMER3 (http://frodo.wi.mit.edu/primer3/), using published data obtained from the NCBI database. Alternatively, for some genes, TaqMan probes (Thermo Fisher Scientific, Waltham, MA, USA) were used, with TaqMan GEX Master Mix (Thermo Fisher Scientific, Waltham, MA, USA). The primer used were as following (forward and reverse): $m$ Gapdh (for CTGAGTATGTCGTGGAGTCTAC; rev GTTGGTGGTGCAGGATGCATTG), $m$ If $n-\gamma$ (for GCTTTGCAGCTCTTCCTCAT; rev ATCCTTTTGCCAGT), $m$ Tnf- $\alpha$ (for CCACCACGCTCTTCTGTCTA; rev AGGGTCTGGGCCATAGAACT), mIl-6 (for CTTCACAAGTCGGAGGCTTA; rev TTCTGCAAGTGCATCATCGT), $\quad m I l-1 \beta$ (for GCTGAAAGCTCTCCACCTCA; $\quad$ rev AGGCCACAGGTATTTTGTCG), $m$ T $g f-\beta$ (for TTGCTTCAGCTCCACAGAGA; $\quad$ rev TGGTTGTAGAGGGCAAGGAC), mIl-10 (for CCCAGAAATCAAGGAGCATT; rev CTCTTCACCTGCTCCACTGC), $\quad m F 4 / 80$ (for TGCAAAAGGATCCTCTTCAAGTG; rev ACTGGGGCACTTTTGTTCTCA), mFoxP3 (for TCTTCGAGGAGCCAGAAGAG; rev AGCTCCCAGCTTCTCCTTTT), $m C d 4$ (for CACCTGGAAGTTCTCTGACCA; rev AAACGATCAAACTGCGAAGG), $m C d 8$ (for GCTCAGTCATCAGCAACTCG; rev GTGCACAGGTGAGGGAGTTC), $m C d 11 b$ (for GTCAGAGTCTGCCTCCGTGT; rev CAGGGTCTAAAGCCAGGTCA), $m C d 49 b$ (for CCATTCGCACCAAGTACTCC; rev ATAGCCATCCAGGGACCTTC), mIl-10ra (for GGTCGGAGGAGCAGTGTTTA; CCAGGATTCCACAGAATAGCA), mIl-10rb (for CATGGGCTTACAGAGTGCAA; rev GTAAGTTGTCCACGGCTCCA), mUcp1 (for CTCACTCAGGATTGTGCCTCTAC; rev TCTGACCTTCACGACCTCTGTA), $\quad m P g c-1 \alpha$ (for CTTAGCACTCAGAACCATGCAG; rev AATGCTCTTCGCTTTATTGCTC), mSrebp1c (for GATCAAAGAGGAGCCAGTGC; rev TAGATGGTGGCTGCTGAGTG), $m F a s$ (for TCAAGATGAAGGTGGCAGAGGTGCT; rev TTGAGCAGTGCCGGGATTCGG), $m C d 36$ (for CGGAGACATGCTTATTGAGAA; rev ACTCTGTATGTGTAAGGACCT; mPpara (for CAGAGGTCCGATTCTTCCAC; GATCAGCATCCCGTGTTTGT), mApoB100 (for GTCCTGGTCAACTTGCAAGC; rev GCTCATACCTTGTGTCCCCT); $\quad m A p o C$ (for GCGTGCAGGAGTCCGATATA; rev GGTTAGAATCCCAGAAGCCG); $m C p t 1 \alpha$ (for TGCCAAATCTCTGCTGCATG; $\quad$ rev GGCCATGACATACTCCCACA), $\quad m F g f 21$ (for CCTGGGTGTCAAAGCCTCTA; rev CTCCAGCAGCAGTTCTCTGA), $m A h R$ (for ATCGCCACTCAGAGACCACT; rev ACAACACAGCCTCTCCGGTA), mCyp1a1 (for ACTCTTCCCTGGATGCCTTC; rev GTCTGTGATGTCCCGGATGT), mCyp1b1 (for TGTGGCTGCTCATCCTCTTT; rev GGTTGGGCTGGTCACTCAT); $h$ GAPDH (for CAGCCTCAAGATCATCAGCA; rev GGTCATGAGTCCTTCCACGA), $h I L-6$ (for CCAGGAGAAGATTCCAAAGATG; GGAAGGTTCAGGTTGTTTTCTG), $h B C L 2$ (for GAAACTTGACAGAGGATCATGC; TCTTTATTTCATGAGGCACGTT), hIL-10R1 (for CCGAGAGTATGAGATTGCCATT; rev 
TCCAGAGGTTAGGAGGCTGA). The expression of marker genes for M1 and M2 macrophage populations were: Cd38 (Mm01220906_m1 ThermoFisher Scientific), and c-myc (Mm00487804_m1 ThermoFisher Scientific).

\subsection{Statistical Analysis}

ANOVA One-way analysis of variance followed by a Tukey test or, alternatively, a two-tailed unpaired Student $t$-test were used for statistical comparisons $\left({ }^{*} p<0.05\right)$ using Prism 6.0 software (GraphPad).

\section{Results}

\subsection{Activity and Specificity of the Natural and Synthetic Pelargonidin Toward AhR}

The natural pelargonidin (Figure 1A, Pelargonidin P) was obtained by the extraction from red radish peels (European variety). The extract was purified by silica gel in reverse phase and the anthocyanins fraction was collected and dried under $\mathrm{N}_{2}$ flux. The pelargonidins purified extract was hydrolyzed in acidic conditions and purified to obtain the aglycon form (see Section 2.2 in Materials and Methods). The methylated pelargonidin (Figure 1A, Mt-P) does not exist in nature, and for this reason it was obtained by de novo synthesis (Scheme 1, Materials and Methods). We first investigated whether the natural $(\mathrm{P})$ and synthetic pelargonidin (Mt-P) (chemical structures shown in Figure 1A) exerted agonistic effects on a family of ligand-activated nuclear receptors, including AhR (Figure S1A,B), PXR, FXR, LXR $\alpha$, and $\beta$, and PPARs and on the G protein-coupled receptor, GPBAR1 (Figure S1C-F).

For this purpose, HepG2 cells, transfected with an AhR reporter gene cloned upstream to the luciferase, were incubated with $5 \mathrm{nM}$ TCDD, an AhR agonist as a control, or vehicle $(0.1 \% \mathrm{v} / \mathrm{v} \mathrm{DMSO})$ in the presence of the two pelargonidins $(0.1-100 \mu \mathrm{M})$ for $18 \mathrm{~h}$. As shown in Figure 1B and Figure S1, both anthocyanins were effective in transactivating the AhR, while they exerted no effect on the other receptors (Figure S1C-F, $p<0.05$ versus control cells). Both pelargonidins produced a concentration-dependent increase of luciferase activity, with a relative potency, expressed as $\mathrm{EC}_{50}$, of 4 and $1.97 \mu \mathrm{M}$ for the natural pelargonidin and Mt-P, respectively (Figure 1B). The interaction of Mt-P with the PAS-B domain of AhR was further investigated by in silico analysis. AhR is a cytosolic signal sensor protein with a multi-modular structure, composed by an amino $\mathrm{N}$-ter domain, namely bHLH domain, which is responsible for DNA binding, two PER-ARNT-SIM domains (PAS A and PAS B), and a carboxy C-ter transactivation domain (TAD). It has been experimentally demonstrated that AhR binds chemically different exogenous ligands at the PAS-B domain [31-34]. In order to get preliminary clues about the mode of interaction between the synthetic pelargonidin, we performed a set of docking studies. Unfortunately, the structure of the PAS B domain of AhR is not yet available, therefore we generated the homology 3D model structure of such a domain, which was used to carry on the docking studies. Figure 1C shows the binding mode of the Mt-P into the PAS B domain of AhR. Key interactions are represented by: (i) Two T- $\pi$ hydrophobic interaction with His291 and Phe351 (blue dashed lines); (ii) a parallel displaced interaction with Phe286 (blue dashed line); (iii) hydrophobic interaction with Thr288, Tyr322, Ile325, Leu353, Val363; and (iv) two h-bonds with His291 and Ser365 (black dashed line). Interestingly, the ability of the Met-P to interact with His291 and Ser365 agrees with experimental data showing that the agonistic effects of AhR binders is mediated by the interaction with these two keys residues [31,32,34]. 
A<smiles></smiles>

Pelargonidin

(P)

C
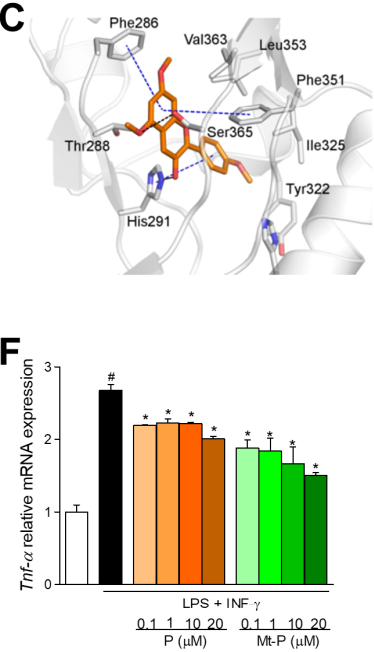

I
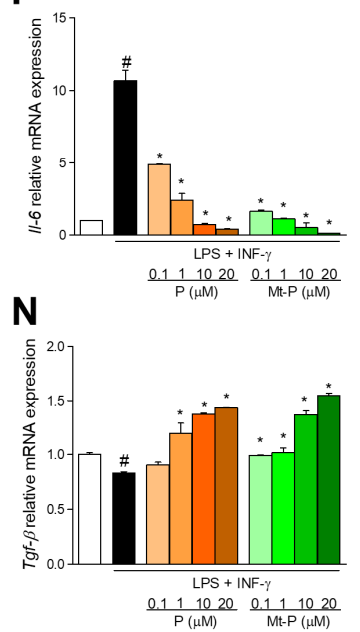

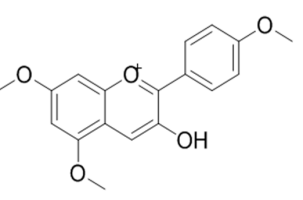

Methylated Pelargonidin (Mt-P)
B

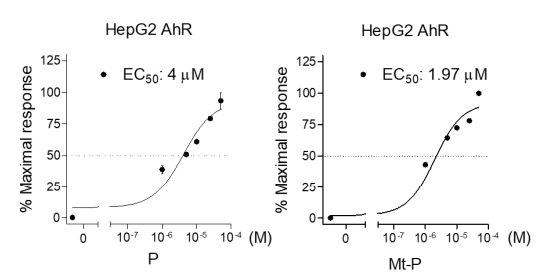

E

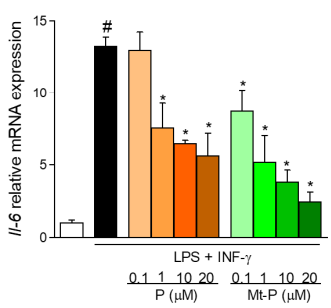

H

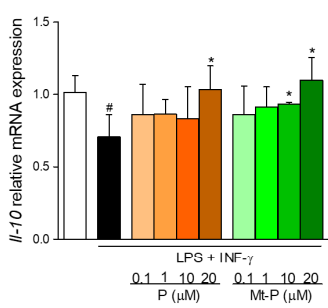

M

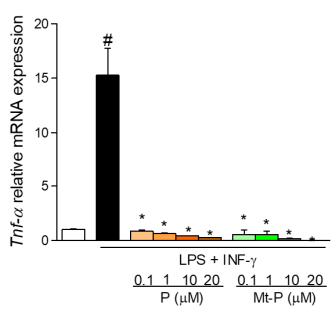

O
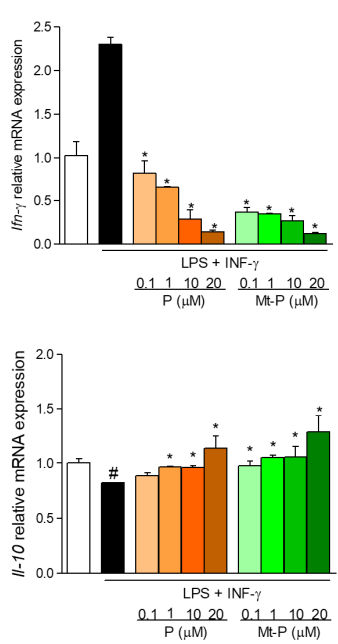

Figure 1. $\mathrm{P}$ and Mt-P counteracts in vitro macrophages and T-cells immune activation. The experiment was carried out on HepG2, Raw264.7 or EL4 cell lines. (A) Molecular structure of P and Mt-P. (B) Concentration-response curves of $\mathrm{P}$ and Mt-P on the aryl hydrocarbon receptor (AhR). HepG2 cells were transiently transfected as described in the Section 2. $24 \mathrm{~h}$ post-transfection cells were stimulated with increasing concentrations of P or Mt-P (1-50 $\mu \mathrm{M})$. TCDD was used as a positive control. (C) Binding model of the Mt-P (orange sticks) into the PAS B domain of the AhR (white cartoon and sticks). Highlighted with dashed black line is the h-bond interaction with His291 and Ser 365, while with dashed blue line is the aromatic interaction. (D-H) In vitro effects of $\mathrm{P}$ and Mt-P on murine macrophages activation. Relative mRNA expression of pro- and anti-inflammatory genes was assessed

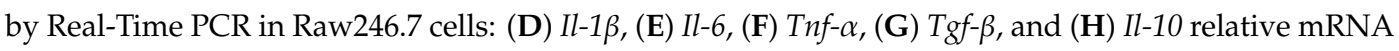
expression. (I-O) In vitro effects of $\mathrm{P}$ and Mt-P on murine T-cells activation. Relative mRNA expression of pro- and anti-inflammatory genes was assessed by Real-Time PCR in EL4 cells: (I) Il-6, (L) Ifn- $\gamma$, (M) Tnf- $\alpha,(\mathbf{N}) T \& f-\beta$, and (O) Il-10. Values are normalized relative to Gapdh mRNA and are expressed as mean $\pm \operatorname{SEM}(n=3) ;{ }^{\#} p<0.05$ vs. NT cells, ${ }^{*} p<0.05$ vs. LPS/IFN- $\gamma$ cells. 


\subsection{In Vitro Characterization of Mt-P on Macrophages and T Cells}

We then investigated whether the Mt-P exerts AhR-dependent activities in vitro. For this purpose, RAW264.7 cells were primed with LPS and IFN- $\gamma$, and co-incubated with or without increasing concentrations of the two pelargonidins. As shown in Figure 1D-F, both pelargonidins were somewhat effective in attenuating the production of pro-inflammatory cytokines (Il-1 $\beta$, Il- 6 , Tnf- $\alpha$ ) in this experimental setting. However, while the natural pelargonidin exerted no effect on Il-1 $\beta$ and caused only a slight reduction of Tnf- $\alpha$ gene transcription, the Mt-P blunted the expression of these inflammatory mediators by 50 to $80 \%$ (Figure 1D-F, ${ }^{\#} p<0.05$ vs. NT cells, ${ }^{*} p<0.05$ vs. LPS/IFN- $\gamma$ cells). Additionally, exposure to the Mt-P increased the expression of anti-inflammatory genes Tgf- $\beta$ and Il-10, while the natural agent exerted no effect or was only minimally effective (Figure 1G,H, ${ }^{\#} p<0.05$ vs. NT cells, ${ }^{*} p<0.05$ vs. LPS/IFN- $\gamma$ cells).

In contrast to the relatively minor effects exerted by the natural pelargonidin on macrophages, both $\mathrm{P}$ and Mt-P were extremely potent in attenuating cytokines generation by T cells (Figure 1I-O). Thus, while priming EL4 T cells with LPS/INF- $\gamma$ increased the expression of Il-6, Ifn- $\gamma$ and Tnf- $\alpha$ (Figure 1I-M, ${ }^{\#} p<0.05$ vs. NT cells, ${ }^{*} p<0.05$ vs. LPS/IFN- $\gamma$ cells) and reduced the expression of Tgf- $\beta$ and Il-10 (Figure $1 \mathrm{~N}-\mathrm{O},{ }^{*} p<0.05$ vs. NT cells, ${ }^{*} p<0.05$ vs. LPS/IFN- $\gamma$ cells), these effects were completely reversed by both agents in a concentration-dependent manner.

To further investigate whether these immune-modulatory effects were mediated by binding/activation of the AhR, spleen-derived macrophages isolated from $\mathrm{AhR}^{+/+}$and $\mathrm{AhR}^{-/-}$mice were incubated with LPS/IFN- $\gamma$ alone or in combination with the two pelargonidins (Figure 2). Once again, both agents reversed the generation of pro-inflammatory mediators caused by exposure to LPS/IFN- $\gamma$ (Figure 2A,B, ${ }^{*} p<0.05$ vs. NT cells, ${ }^{*} p<0.05$ vs. LPS/IFN- $\gamma$ cells), while induced an up-regulation of the anti-inflammatory cytokines $I l-10$ and $T g f-\beta$, but this effect was completely abrogated by AhR gene ablation (Figure $2 \mathrm{~A}-\mathrm{D},{ }^{*} p<0.05$ vs. NT cells, ${ }^{*} p<0.05$ vs. LPS/IFN- $\gamma$ cells). 
A

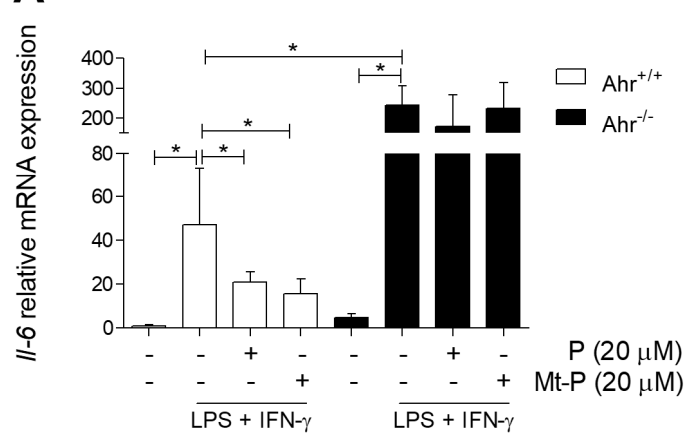

C

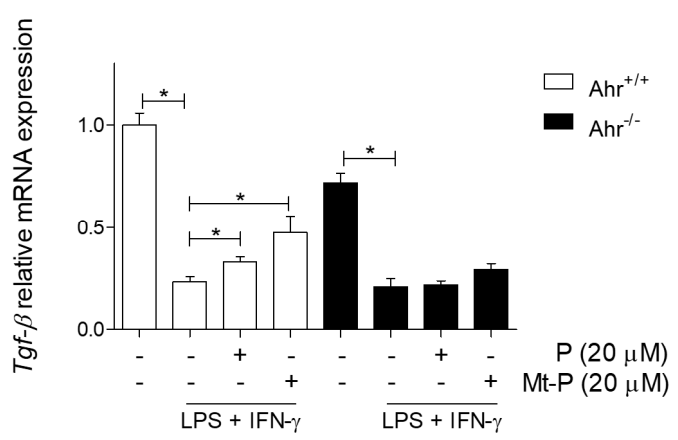

B

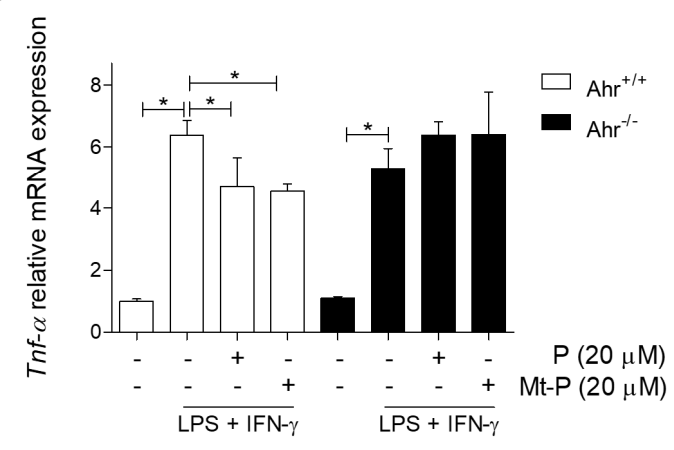

D

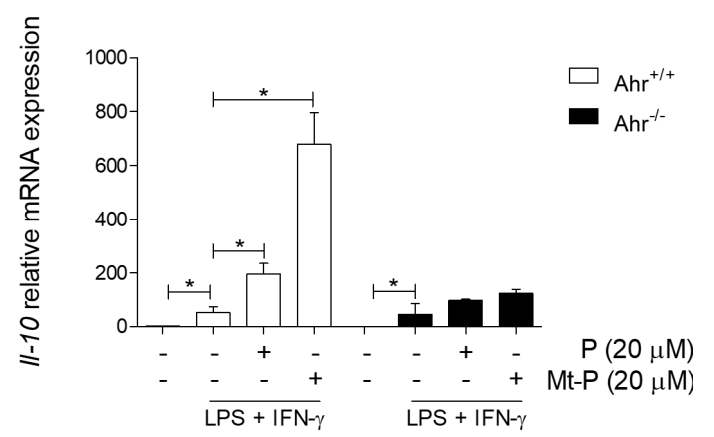

Figure 2. $\mathrm{P}$ and Mt-P counteracts in vitro macrophages immune activation through the AhR. The experiment was carried out on macrophages purified by the spleen of $\mathrm{AhR}^{+/+}$and $\mathrm{AhR}^{-/-}$mice. Macrophages cells were primed $16 \mathrm{~h}$ with LPS $(5 \mathrm{ng} / \mathrm{mL}) / \mathrm{IFN}-\gamma(20 \mathrm{ng} / \mathrm{mL})$ alone or in combination with $\mathrm{P}(20 \mu \mathrm{M})$ and Mt-P $(20 \mu \mathrm{M})$. At the end of stimulation, the relative mRNA expression of pro-inflammatory cytokines (A) Il-6 and (B) Tnf- $\alpha$, and anti-inflammatory cytokines (C) Tgf- $\beta$ and (D) Il-10, was assessed by Real-Time PCR. Values are normalized relative to Gapdh mRNA and are expressed as mean $\pm \operatorname{SEM}(n=4) ;{ }^{*} p<0.05$.

\subsection{In Vitro Characterization of Mt-P on Intestinal Epithelial Cells}

Since intestinal epithelial cells express $\mathrm{AhR}$ and the receptor is involved in maintenance of intestinal barrier function, we then investigated whether $\mathrm{P}$ and Mt-P promote $\mathrm{CaCo}-2$ cells migration in an in vitro model of wound healing, an indirect measure of the ability of intestinal epithelial cells to repair mucosal injuries and maintain intestinal barrier integrity. As shown in Figure 3A,B, treating $\mathrm{CaCo} 2$ cells with LPS impaired the wound closure in this model. Conversely, Mt-P reversed the effect of LPS, greatly accelerating the wound closure to the same extent of TGF- $\beta$, a potent inducer of $\mathrm{CaCo} 2$ cell migration, that was used as positive control (Figure $3 \mathrm{~A}, \mathrm{~B},{ }^{*} p<0.05$ vs. NT cells, ${ }^{*} p<0.05$ vs. TGF- $\beta$ cells). 
A
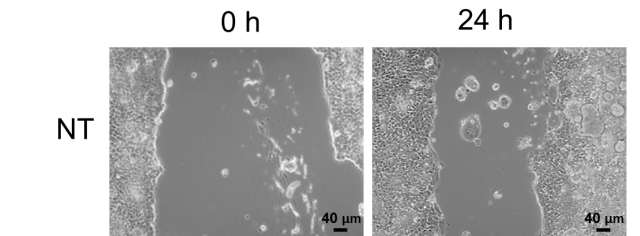

TGF $\beta$
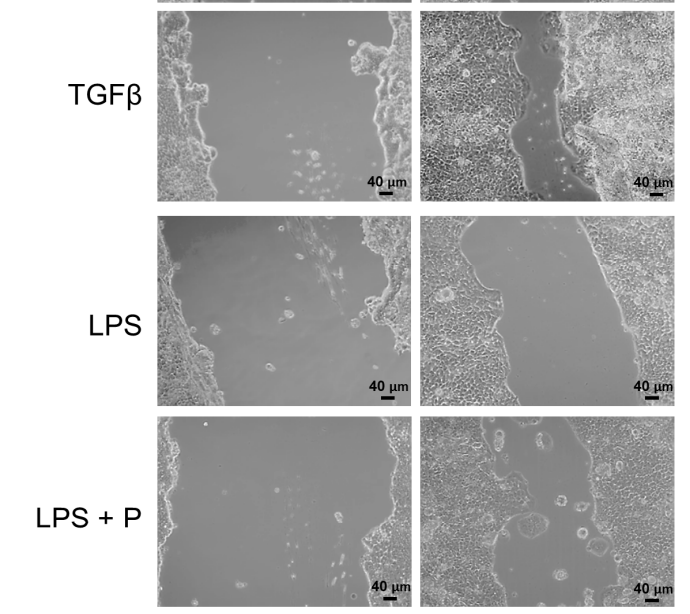

\section{B}
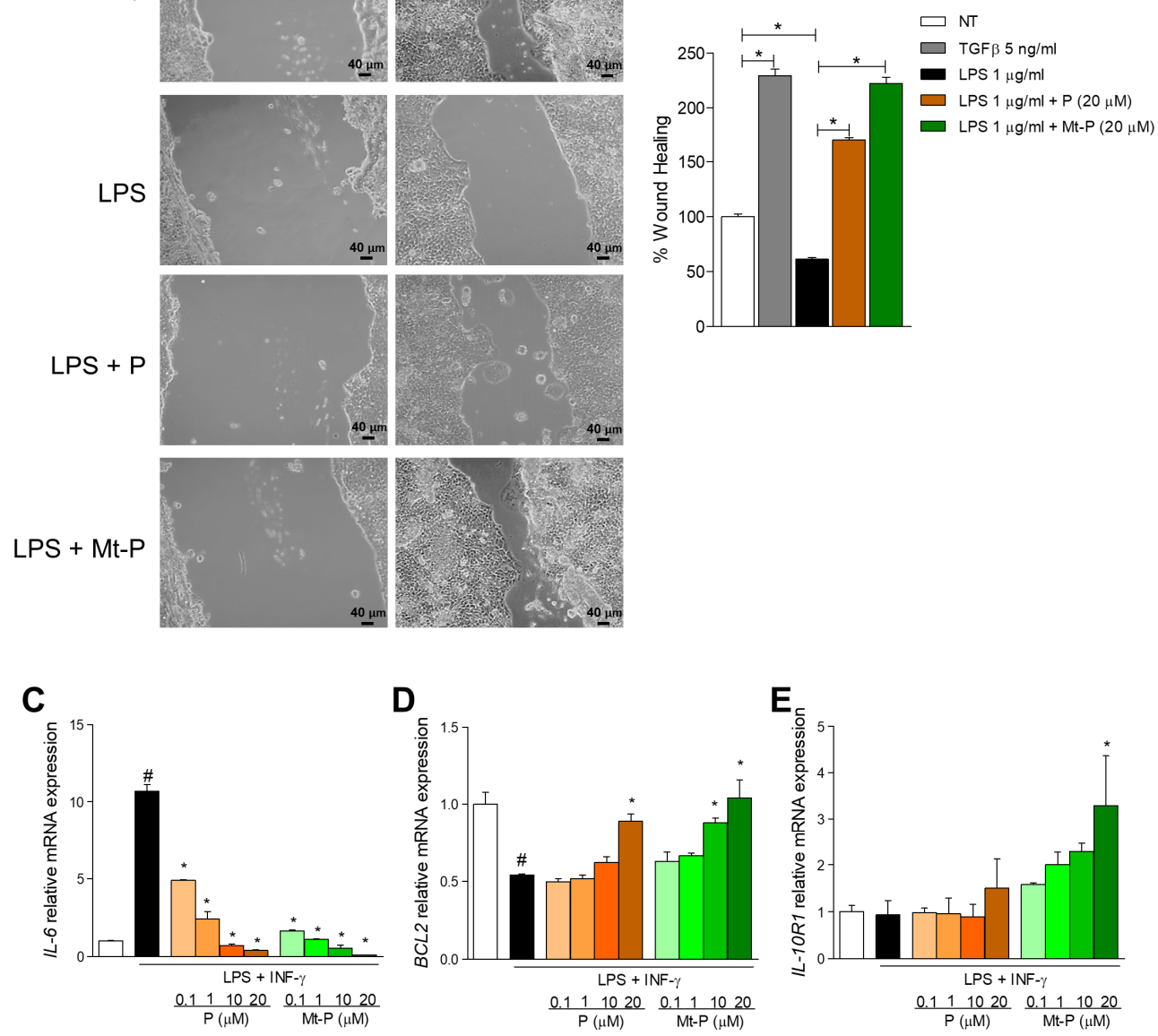

Figure 3. $\mathrm{P}$ and Mt-P accelerates the wound healing in Caco-2 cells, reducing inflammation and apoptosis. Confluent Caco-2 cell monolayers were wounded with a pipette tip and incubated with medium alone (NT), TGF $\beta(5 \mathrm{ng} / \mathrm{mL})$ used as positive control, LPS $(1 \mu \mathrm{g} / \mathrm{mL})$ alone or in combination with P and Mt-P $(20 \mu \mathrm{M})$ for $24 \mathrm{~h}$. (A) Representative images of scratched areas at 0 and $24 \mathrm{~h}$ (Magnification 10X). (B) Percentage of wound healing at $24 \mathrm{~h}$ after scratch (five wells of three fields each) (NT wells were arbitrarily assigned as 100\%). Wound healing was photographed at 0 and $24 \mathrm{~h}$ after scratch. Results are expressed as mean \pm S.E.M. and analyzed using ANOVA followed by Bonferroni's test. ${ }^{*} p<0.05$ compared to control group. (C-E) In vitro effects of P and Mt-P on human intestinal epithelial cell activation. Serum-starved Caco- 2 cells were primed $16 \mathrm{~h}$ with LPS $(5 \mathrm{ng} / \mathrm{mL}) / \mathrm{IFN}-\gamma$ $(20 \mathrm{ng} / \mathrm{mL})$ alone or in combination with increasing concentration of both $\mathrm{P}$ and Mt-P $(0.1-20 \mu \mathrm{M})$. At the end of stimulation, the relative mRNA expression of pro-inflammatory gene IL-6, anti-apoptotic gene BCL-2, and IL-10R1, was assessed by Real-Time PCR. Values are normalized relative to GAPDH mRNA and are expressed relative to those of not treated cells (NT), which are arbitrarily set to $1(n=3$, ${ }^{\#} p<0.05$ vs. NT, ${ }^{*} p<0.05$ vs. LPS). 
To gain some mechanistic insights into this model, we assessed the effect of $\mathrm{P}$ and Mt-P on the expression of IL-6, BCL2, and IL-10R1 genes in CaCo2 cells exposed to LPS/IFN- $\gamma$, and found that bot agents completely abrogated IL-6 mRNA transcription in a concentration-dependent manner (Figure 3C, ${ }^{\#} p<0.05$ vs. NT cells, ${ }^{*} p<0.05$ vs. LPS/IFN- $\gamma$ cells). Moreover, Mt-P increased the expression of the anti-apoptotic gene $B C L 2$ (Figure $3 \mathrm{D},{ }^{\#} p<0.05 \mathrm{vs}$. NT cells, ${ }^{*} p<0.05 \mathrm{vs}$. LPS/IFN- $\gamma$ cells), as well expression of $I L-10 R 1$ (Figure $3 \mathrm{E},{ }^{\#} p<0.05$ vs. NT cells, ${ }^{*} p<0.05$ vs. LPS/IFN- $\gamma$ cells) mRNA, a gene encoding the interleukin 10 receptor 1 , which is known to induce the proliferation of intestinal epithelial cells [35].

\subsection{Mt-P Rescues from Intestinal Inflammation in an AhR-Dependent Manner}

We then investigated whether pelargonidins attenuate intestinal inflammation and immune dysfunction in a mouse model of colitis, induced by treating BALB/c mice with TNBS. The results shown in Figure S2 demonstrate that the development of clinical signs and symptoms of intestinal inflammation and their severity were greatly attenuated by treatment with both $\mathrm{P}$ and Mt-P, though only the effect of Mt-P was dose-dependent over the range of concentrations tested. Indeed, while doses of 5-10 mg/kg P were required to prevent development of all clinical signs and symptoms of colitis (Figure S2C-F; ${ }^{*} p<0.05$ vs. NT mice, ${ }^{*} p<0.05$ vs. TNBS mice), a dose of $5 \mathrm{mg} / \mathrm{kg}$ of Mt-P successfully reversed inflammatory changes caused by TNBS (Figure S2, ${ }^{\#} p<0.05$ vs. NT mice, $* p<0.05$ vs. TNBS mice).

Because these data suggest that $5 \mathrm{mg} / \mathrm{kg}$ of Mt-P was fully effective in reversing signs of intestinal inflammation, we investigated the mechanisms involved in the beneficial effects exerted by this agent, in comparison to the natural pelargonidin, on intestinal immunity. Again, as shown in Figure 4, Mt-P at the dose of $5 \mathrm{mg} / \mathrm{kg}$ was significantly more effective than $\mathrm{P}$ in protecting from appearance of the clinical signs of colitis (body weight loss and CDAI), and was significantly more effective in attenuating macroscopic changes caused by TNBS (Figure $4 \mathrm{~A}-\mathrm{C},{ }^{*} p<0.05$ ). Additionally, while treating mice with TNBS increased the colonic expression of Il-6, Tnf- $\alpha, I l-1 \beta$ and Ifn- $\gamma$, (Figure $4 \mathrm{D},{ }^{*} p<0.05$ ), this pattern was fully reversed by treatment with the Mt-P, that also increased the colonic expression of Tgf- $\beta$ and Il-10 mRNA (Figure 4E, * $p<0.05$ ). 

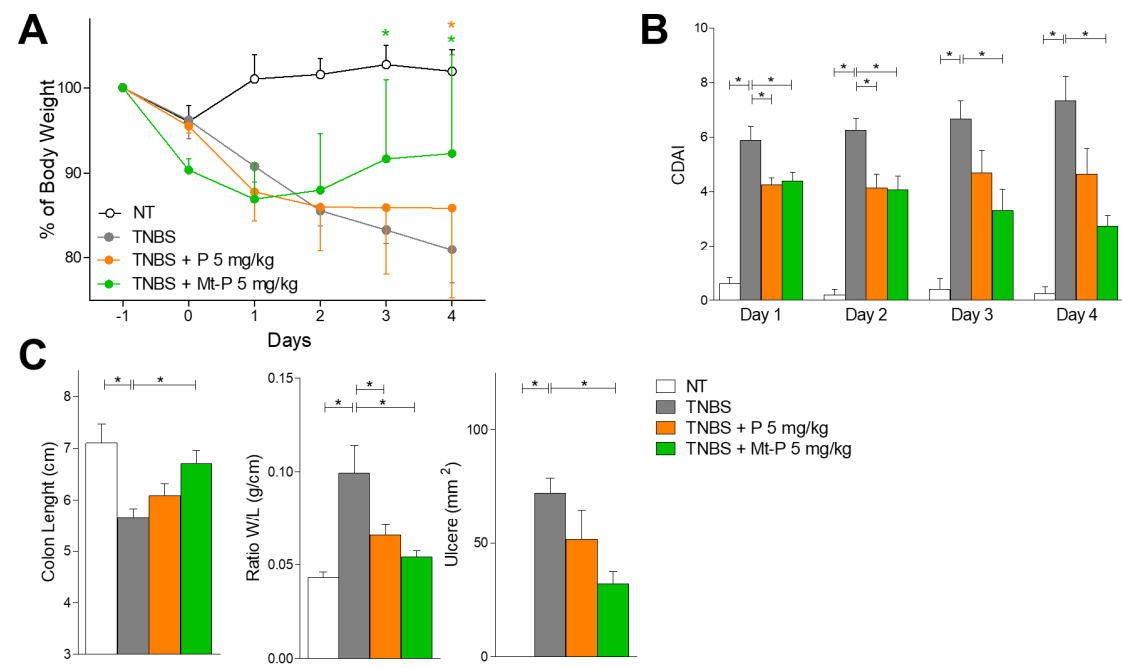

D
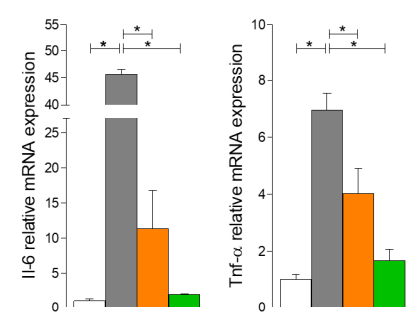

F

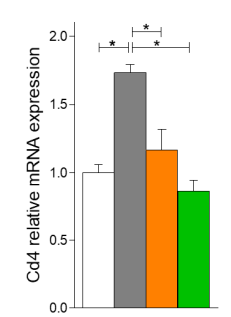

H

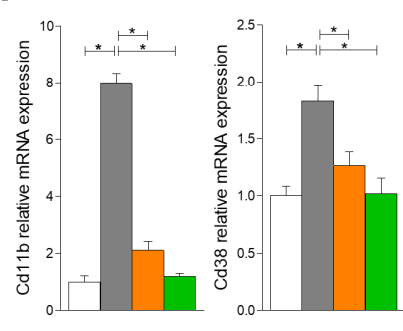

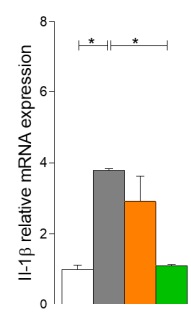

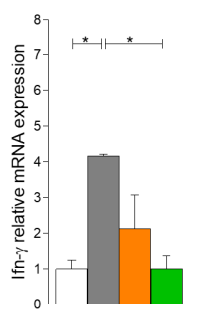

G
E
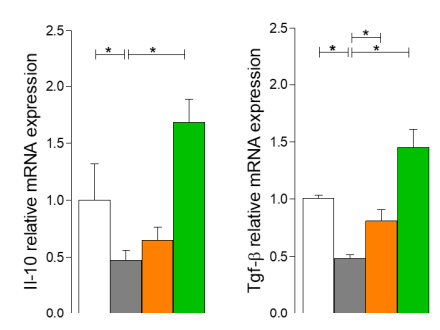

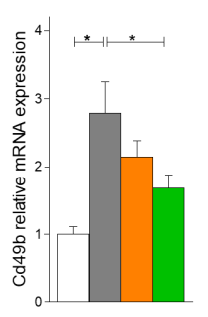

I
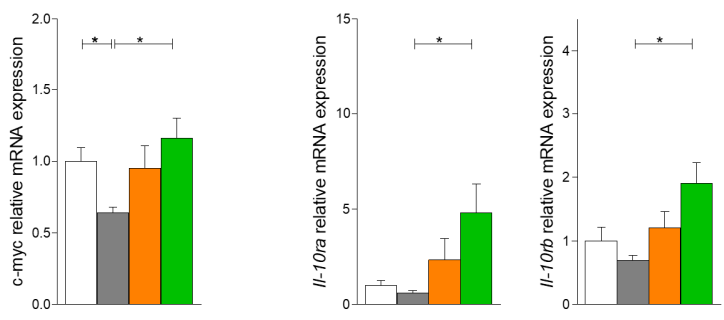

Figure 4. Mt-P is more effective than $\mathrm{P}$ in reducing the severity of colitis. Balb/C mice were treated with TNBS alone or in combination with P or Mt-P $(5 \mathrm{mg} / \mathrm{kg})$ as described before (see Section 2). (A) Changes in body weight and (B) Colitis Disease Activity Index (CDAI) of mice during the course of TNBS-induced colitis. (C) Analysis of the intestinal inflammatory score: Colon length (left), ratio of colon weight/colon length (central), and ulcers (right). Relative mRNA expression of pro-inflammatory cytokines (D) Il-6, Tnf- $\alpha$, Il-1 $\beta$, and Ifn- $\gamma$, (E) anti-inflammatory cytokines $I l-10$ and Tgf- $\beta$, (F) T cell markers $C d 4, C d 8$, and FoxP3, (G) NK and NKT markers Cd49b, (H) macrophages markers Cd11b, Cd38, and $c-m y c$, and (I) Il-10ra and Il-10rb genes in the colons of mice assessed by real-time PCR. Values are normalized relative to Gapdh mRNA and are expressed as mean \pm SEM of five/eight mice per group $(\mathrm{NT}=5 ; \mathrm{TNBS}=8 ; \mathrm{TNBS}+\mathrm{P} 5 \mathrm{mg} / \mathrm{kg}=6 ; \mathrm{TNBS}+\mathrm{Mt}-\mathrm{P} 5 \mathrm{mg} / \mathrm{kg}=8)\left({ }^{*} p<0.05\right)$. 
Amelioration of macroscopic signs of colitis correlated with a robust attenuation of inflow of inflammatory cells in the colonic lamina propria, as shown in Figure $4 \mathrm{~F}-\mathrm{H}$. Again, while treatment with Mt-P significantly reduced the polarization of colonic cell infiltrates toward a pro-inflammatory phenotype, as assessed by measuring the levels of expression of $C d 11 b, C d 8, C d 4, C D 49 b$, and $C d 38$, this pattern was only partially reproduced by the natural pelargonidin. Additionally, as shown in Figure 4F-I, Mt-P, but not the natural pelargonidin, increased the expression of $c-m y c$, a M2 marker, and FoxP3, a Treg marker (Figure $4 \mathrm{~F}-\mathrm{I},{ }^{*} p<0.05$ ). The later effects were not observed in mice treated with the natural pelargonidin.

These findings were confirmed by a flow-cytometry analysis of colonic lamina propria infiltrating cells (Figure 5A-C), demonstrating that protection exerted by Mt-P associated with, and increased recruitment of, CD4+ FoxP3+ (Treg cells) in the lamina propria. Furthermore, analysis of macrophage subsets demonstrated that the in vivo exposure to the two agents increased the polarization of colonic macrophages toward a Cd11b+/IL-10+ anti-inflammatory phenotype (Figure 5D-F).

To investigate whether the mechanism of action of $\mathrm{P}$ and Mt-P in vivo requires an intact AhR signaling, we then assessed the expression of the receptor, along with AhR-regulated genes in the colons of mice treated with TBNS and found that, while TNBS administration decreased the colonic expression of AhR mRNA and its target genes Cyp1a1 and Cyp1b1, this pattern was reversed by treating mice with Mt-P, while the natural compound was ineffective (Figure $6 \mathrm{~A}-\mathrm{C},{ }^{*} p<0.05$ ).

To further elaborate on the mechanism involved in the regulation of AhR-regulated genes in vivo, we assessed whether exposure to $\mathrm{P}$ and Mt-P resulted in the occupation of Cyp1a1 promoter by the AhR. Because the analysis of Cyp1a1 promoter revealed the presence of binding sequences for the AhR/ARNT dimer (see Section 2), we carried out a ChIP assay on RAW264.7 cells to investigate whether exposure to $\mathrm{P}$ and Mt-P increased the binding of the AhR/ARNT dimer to the Cyp1a1 promoter. As shown in Figure 6D, while exposure to LPS slightly reduced the occupation of Cyp1a1 promoter by the AhR/ARNT dimer, this effect was reversed by both P and Mt-P, but the synthetic compound was significantly more effective and increased the binding of the AhR/ARNT dimer to the Cyp1a1 promoter by almost three-fold (Figure $6 \mathrm{E},{ }^{*} p<0.05$ vs. LPS treated cells).

We next investigated whether the anti-inflammatory activities of Mt-P are maintained in AhR-knockout mice. For this purpose, wild-type and $\mathrm{AhR}^{-/-}$mice on a C57BL/6 background were administered TNBS ( 0.5 or $1 \mathrm{mg} / \mathrm{mice})$, with or without Mt-P $(5 \mathrm{mg} / \mathrm{kg})$. As shown in Figure 7 , the severity of disease was exacerbated by AhR gene ablation. In comparison with their congenic littermates, $\mathrm{AhR}^{-/-}$mice developed an aggressive disease associated with a high rate mortality on day $4(70 \%$ versus $25 \%)$, as shown in Figure 7A. Furthermore, while treatment with Mt-P protected from colitis development in $\mathrm{AhR}^{+/+}$mice, the protective effects were lost in $\mathrm{AhR}^{-/-}$mice (Figure $7 \mathrm{~B}, \mathrm{C}$ ). 
A

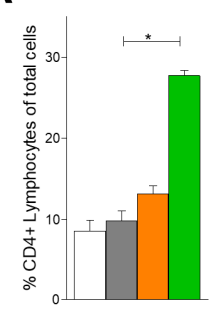

B

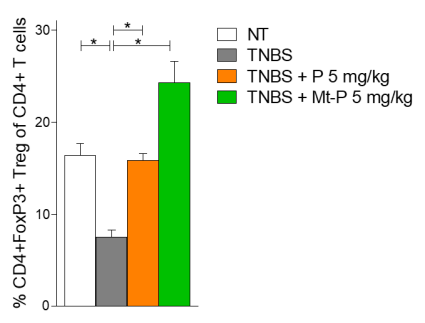

C

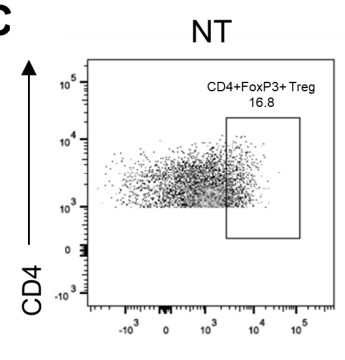

TNBS

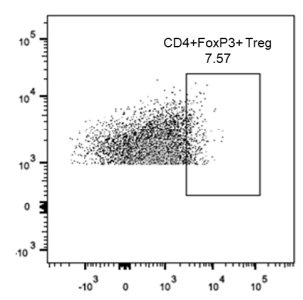

TNBS $+\mathrm{P}$

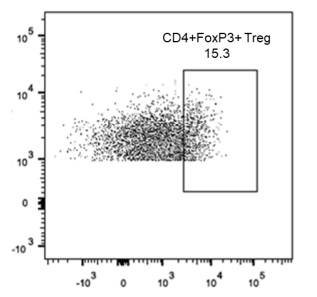

TNBS + Mt-P

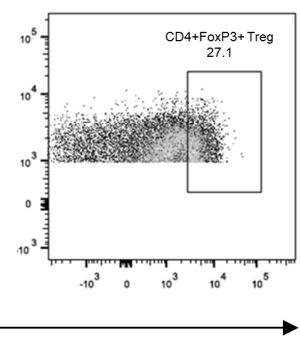

FoxP3

D

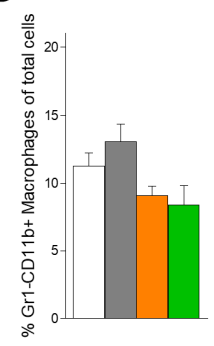

$\mathbf{F}$

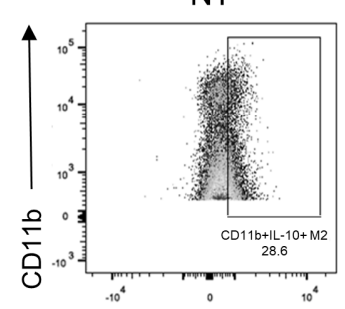

IL-10

\section{E}

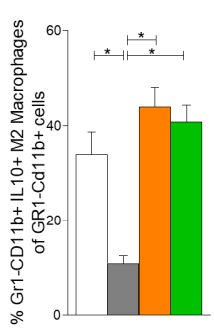

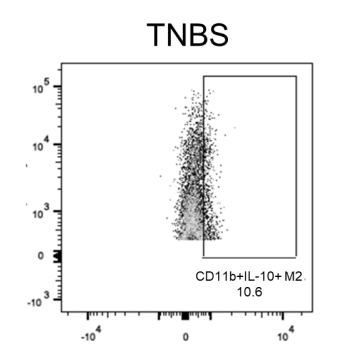
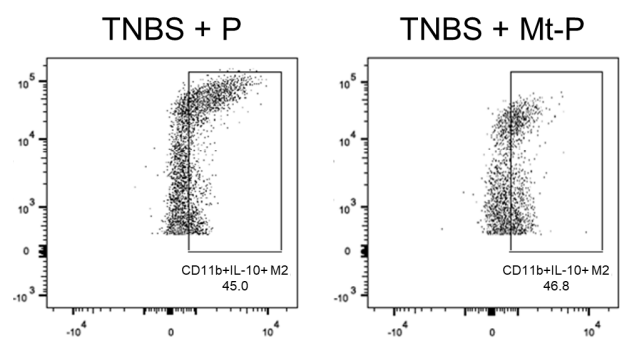

Figure 5. Effect of $\mathrm{P}$ and Mt-P on the polarization of the LP immune cells in the TNBS model of colitis. Frequency of immune cells in the colonic lamina propria (LP): (A) CD4+ cells and (B) CD4+FoxP3+ cells. (C) Flow cytometry analysis of FoxP3 expression in CD4+ cell recruited into the LP. Frequency of (D) CD11b+Gr1-macrophages and (E) CD11b+Gr1-IL-10+ M2 macrophages in the colonic LP. (F) Flow cytometry analysis of Il-10 expression in CD11b+Gr1-macrophages recruited into the LP. Results are the mean $\pm \mathrm{SEM}$ of five/eight mice per group $(\mathrm{NT}=5 ; \mathrm{TNBS}=8$; TNBS $+\mathrm{P} 5 \mathrm{mg} / \mathrm{kg}=6$; TNBS + Mt-P $5 \mathrm{mg} / \mathrm{kg}=8) .\left({ }^{*} p<0.05\right)$. 
A

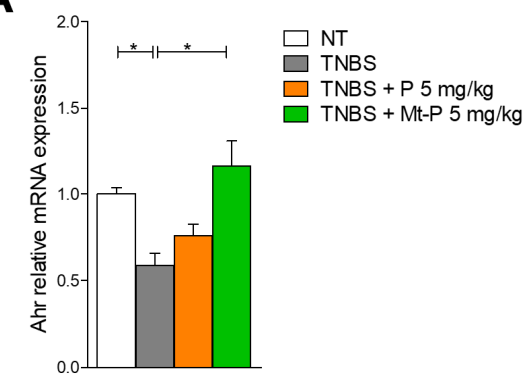

D

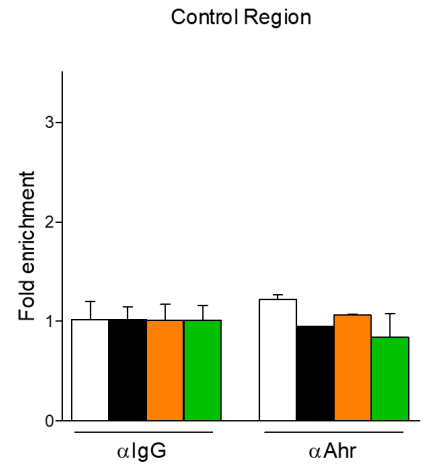

B

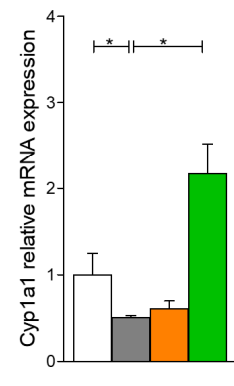

C

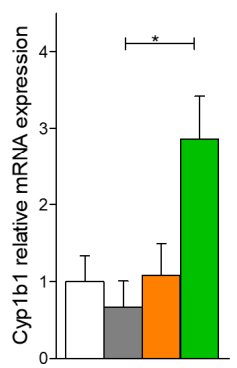

Cyp $1 \alpha 1$ Promoter

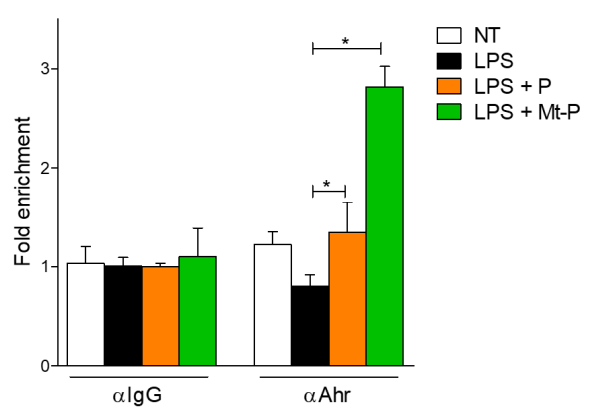

Figure 6. $\mathrm{P}$ and Mt-P activate the aryl hydrocarbon receptor (AhR). Relative mRNA expression of (A) AhR, (B) CYP1a1, and (C) CYP1b1 genes in the colons of mice treated with TNBS alone or in combination with P or Mt-P, assessed by real-time PCR. Data are normalized to Gapdh mRNA. Results are the mean \pm SEM of five/eight mice per group $(\mathrm{NT}=5$; TNBS $=8$; TNBS $+\mathrm{P} 5 \mathrm{mg} / \mathrm{kg}=6$; TNBS + Mt-P $5 \mathrm{mg} / \mathrm{kg}=8)\left({ }^{*} p<0.05\right)$. (D) ChIP assay of the AhR binding Cyp1a1 promoter in Raw264.7 cells. Cell lysates were immunoprecipitated with anti-AhR or control IgG, and the presence of specific regions in the immune-precipitates was determined by RT-PCR. $(n=3)\left({ }^{*} p<0.05\right)$.

Since glucocorticoids are widely used in the treatment of IBDs, we compared the beneficial effects of Mt-P to dexamethasone in the treatment of colitis induced by TNBS. The data shown in Figure S3A,B, demonstrate that both Mt-P and dexamethasone effectively attenuated the development of wasting disease and disease severity (Figure S3B, ${ }^{*} p<0.05$ ), and exerted similar beneficial effects on colon length, colon weight/length ratio, and number of ulcerations (Figure S3C-E, ${ }^{*} p<0.05$ ). 
A

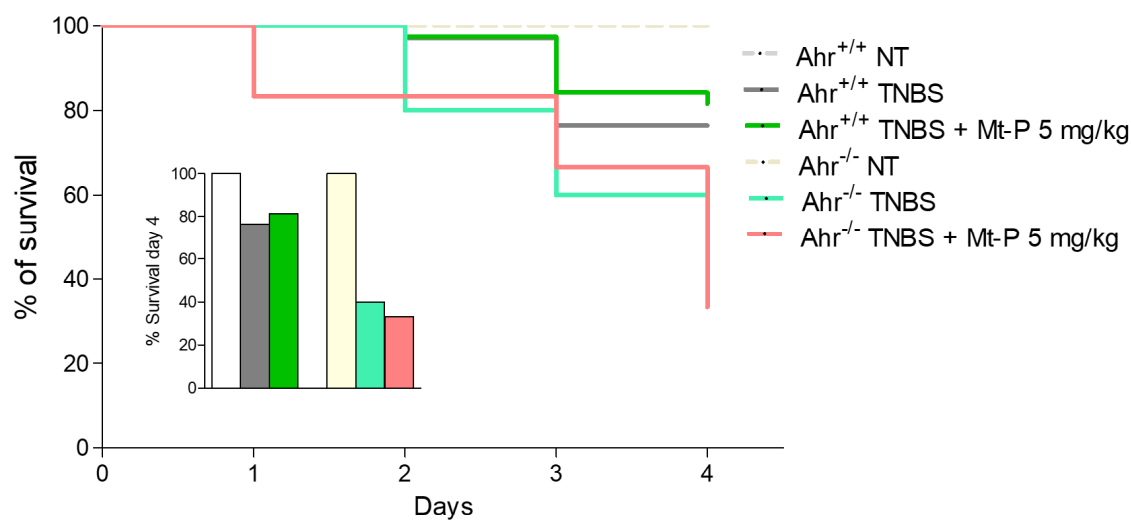

B

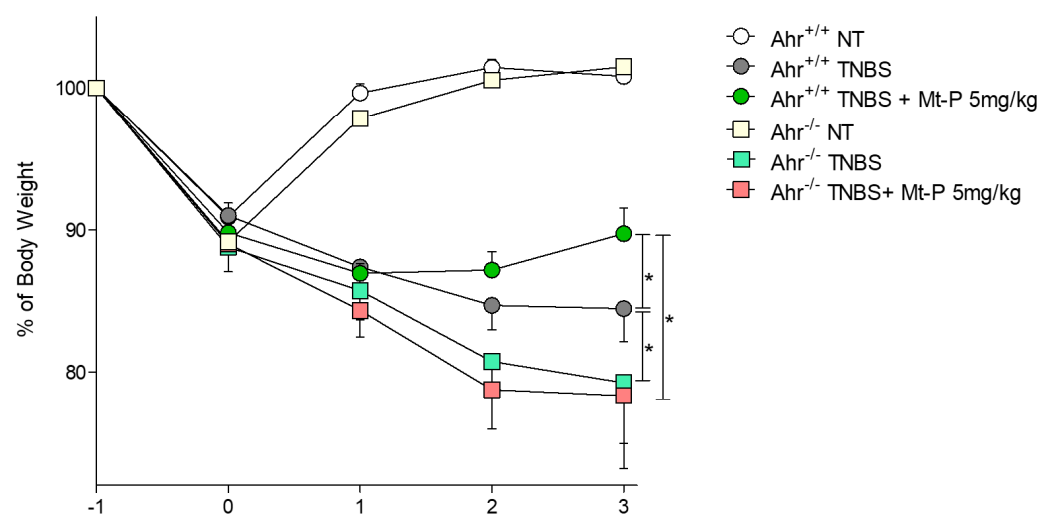

C

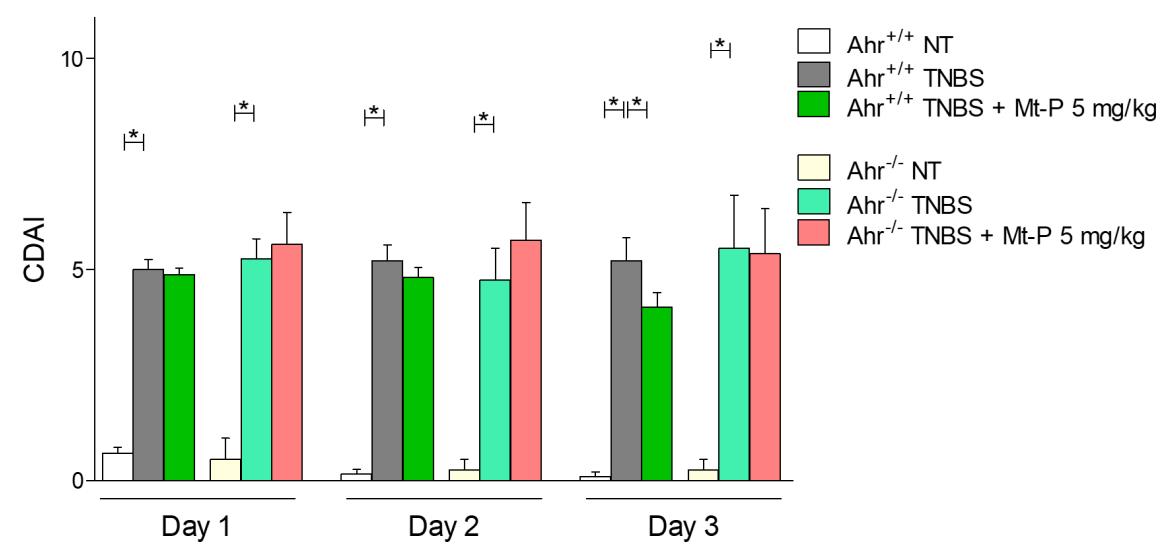

Figure 7. The beneficial effect of Mt-P is lost in $\mathrm{AhR}^{-/-}$mice. $\mathrm{AhR}^{+/+}$and $\mathrm{AhR}^{-/-}$mice were treated with $1 \mathrm{mg}$ of TNBS and then administered vehicle or Mt-P $(5 \mathrm{mg} / \mathrm{kg} / \mathrm{d})$ by gavage from days 0 to 4 . Treatment with Mt-P attenuated the development of disease only in $\mathrm{AhR}^{+/+}$mice, on the contrary AhR gene ablation aggravated the disease. The disease was monitored by (A) percentage of survival, (B) changes in body weight, and (C) CDAI score. Results are the mean \pm SEM of five/twelve mice per group $\left(\mathrm{Ahr}^{+/+} \mathrm{NT}=8 ; \mathrm{Ahr}^{+/+} \mathrm{TNBS}=10 ; \mathrm{Ahr}^{+/+} \mathrm{TNBS}+\mathrm{Mt}-\mathrm{P} 5 \mathrm{mg} / \mathrm{kg}=12 ; \mathrm{Ahr}^{-/-} \mathrm{NT}=5 ; \mathrm{Ahr}^{-/-}\right.$ TNBS $=5 ; \mathrm{Ahr}^{-1-}$ TNBS + Mt-P $\left.5 \mathrm{mg} / \mathrm{kg}=6\right)\left({ }^{*} p<0.05\right)$. 


\subsection{Mt-P Attenuates Intestinal Inflammation and Insulin Resistance in Mice Fed a HFD-F}

To test whether therapeutic potentials of Mt-P extended beyond the intestine, we set up a model of intestinal inflammation in the frame of metabolic dysfunction caused by feeding mice HFD-F for 8 weeks. As shown in Figure 8, mice exposed to chronic high caloric intake gained significantly more body weight than mice feed a normal chow diet, and they had significantly higher BMI at the end of the study (Figure $8 \mathrm{~A}, \mathrm{~B},{ }^{*} p<0.05$ ).

A

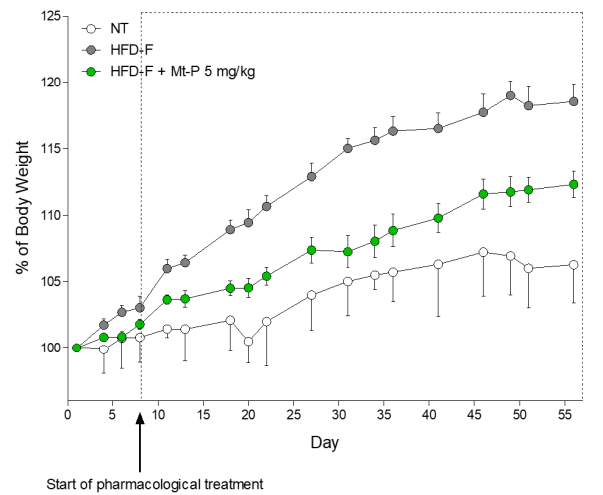

C

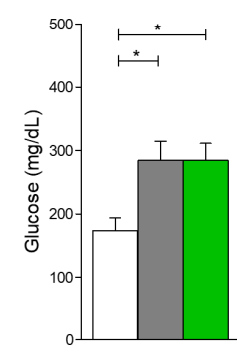

B
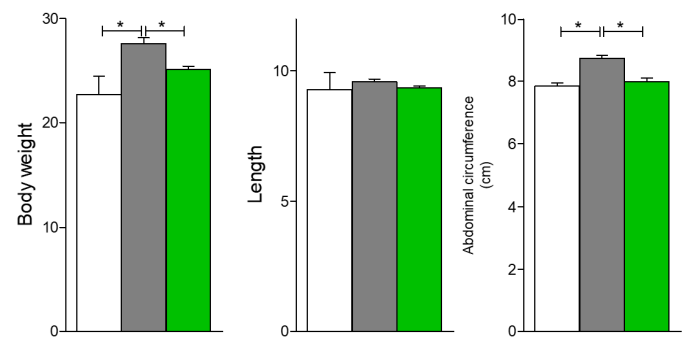

$\mathbf{E}$

D

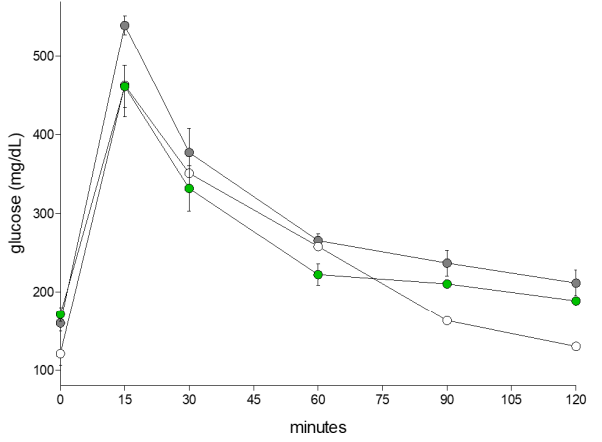

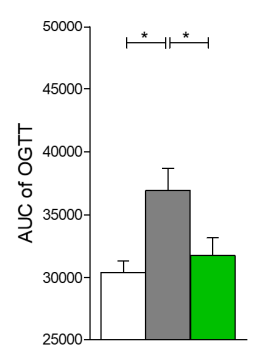

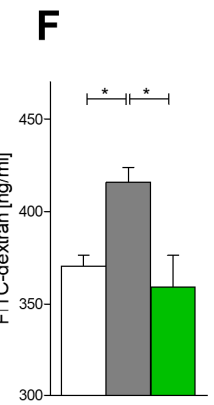

G

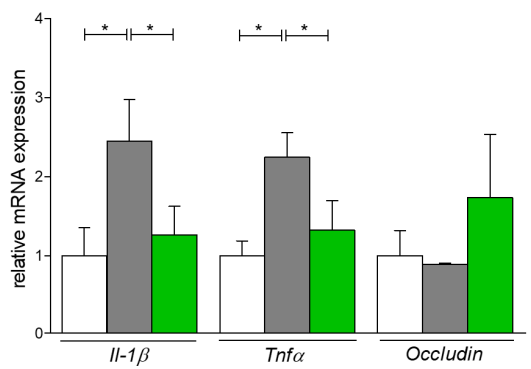

Figure 8. Activation of AhR reduced body weight gain and insulin resistance in mice fed a HFD-F. C57BL/6 male mice were fed a high fat diet (HFD) and fructose or normal chow diet as described before (see Section 2). (A) Changes in body weight (\%) assessed weekly. Anthropometrical parameters: (B) Body mass index (BMI) measured at the end of the study; (C) glucose plasma levels; (D) glucose levels in response to OGTT; and (E) Air Under the Curve (AUCs) of glucose plasma levels expressed in arbitrary units. Results in intestine: (F) Intestinal permeability was measured after 2 weeks of diet with FITC-dextran; and (G) quantitative RT-PCR analysis of $I l-1 \beta, \operatorname{Tnf} \alpha$, and occludin1. Values are normalized relative to Gapdh mRNA and are expressed as mean \pm SEM of six/ten mice per group (NT = 6; HFD-F = 8; HFD-F + Mt-P $5 \mathrm{mg} / \mathrm{kg}=10)\left({ }^{*} p<0.05\right)$. 
Treating mice with $5 \mathrm{mg} / \mathrm{kg} /$ day Mt-P for 8 weeks protected against body weight gain and resulted in a lower BMI in comparison to mice feed a HFD-F (Figure 8A,B, ${ }^{*} p<0.05$ ). After 8 weeks of feeding a HFD-F, mice developed insulin resistance, as demonstrated by higher glucose plasma levels, and altered glucose levels in response to OGTT in comparison to naïve mice (Figure $8 \mathrm{C}-\mathrm{E}$ ). Treating mice with Mt-P effectively improved the glucose tolerance test and reduced the Air Under the Curve (AUC) of OGTT (Figure 8D,E, * $p<0.05$ ).

Analysis of intestine functionality in this model demonstrated that chronic exposure to a high caloric intake increased dramatically the intestinal permeability (Figure 8F), as measured by assessing plasma levels of the FITC dextran at the end of the study, along with expression of colonic markers of inflammation such as $I l-1 \beta$ and Tnf- $\alpha$ (Figure $8 \mathrm{G}$ ). These changes were completely reversed by treating HFD-F mice with Mt-P (Figure 8F,G, ${ }^{*} p<0.05$ ). While no effects were observed in HFD-F mice, Mt-P administration increased the expression of occludin mRNA, thus confirming a decreased intestinal permeability (Figure $8 \mathrm{~F}$ ).

We then characterized the effects of Mt-P on plasma and liver biochemistry in mice feed HFD-F. As shown in Figure 9, at the time of sacrifice, mice feed a HFD-F alone had increased plasma levels of triglycerides and cholesterol (Total HDL and LDL) (Figure 9A-D, ${ }^{*} p<0.05$ ). This pattern was reversed by Mt-P, with the exception of HDL cholesterol (Figure $9 \mathrm{C},{ }^{*} p<0.05$ ).

Mice challenged with HFD-F for 8 weeks developed NASH-like features, as demonstrated by H\&E staining of liver sections, with micro-vesicular steatosis and hepatocytes ballooning (Figure 9E), which resulted in a marked increase in the liver steatosis score (Figure $9 \mathrm{~F},{ }^{*} p<0.05$ ). Furthermore, exposure to a HFD-F increased liver collagen deposition, resulting in moderate fibrosis, as shown by scoring Sirius red stained liver sections (Figure $9 \mathrm{G}, \mathrm{H},{ }^{*} p<0.05$ ). To some surprise, despite an improvement in body weight and insulin resistance, treating HFD-F mice with Mt-P worsened lipid accumulation, resulting in severe steatosis as shown by H\&E staining, with no deterioration of liver fibrosis (Figure 9E-H, ${ }^{*} p<0.05$ ). Treating mice with Mt-P failed to ameliorate liver steatosis and fibrosis (Figure $9 \mathrm{E}-\mathrm{H},{ }^{*} p<0.05$ ).

Since liver steatosis in mice feed HFD-F is the result of impaired triglycerides synthesis, fatty acid oxidation, or lipid uptake, we then investigated the expression of genes involved in the regulation of these pathways. Interestingly, as shown in Figure 9I, mice treated with Mt-P had a reduced expression of lipogenic genes such as Srebp1c and Fas, compared with HFD-F mice (Figure 9I, ${ }^{*} p<0.05$ ), while the expression of fatty acid oxidation genes, including Ppar $\alpha$ and its target gene Cpt1 $\alpha$, was significantly decreased in HFD-F mice administered the AhR ligand. Furthermore, AhR activation in the liver resulted in an impaired triglyceride secretion by hepatocytes, as indicated by reduced expression of genes involved in very low-density lipoprotein (VLDL) formation, such as Apob100 and ApoC (Figure 9J, $\left.{ }^{*} p<0.05\right)$. The analysis of inflammatory markers revealed that mice on HFD-F had an increased liver expression of pro-inflammatory genes such as Il-6, Tnf $\alpha, I l-1 \beta$ (Figure 9J). This pattern was attenuated by treating mice with Mt-P (Figure 9J, ${ }^{*} p<0.05$ ). Moreover, Mt-P increased the expression of $A h R$ and its target genes, including Cyp1a1, Cyp1b1, and Fgf21 (Figure 9J, ${ }^{*} p<0.05$ ), confirming the in vivo efficacy of the compound.

We then investigated the metabolic effects of AhR activation in metabolic tissues, including the epididymal white adipose tissue (eWAT). As shown in Figure 10, exposure to the HFD-F increased the eWAT weight (Figure 10A) and induced several morphological changes, including a reduction of the number of adipocytes, while increased their size, as revealed by the analysis of H\&E staining sections (Figure 10B-D, ${ }^{*} p<0.05$ ). 
A

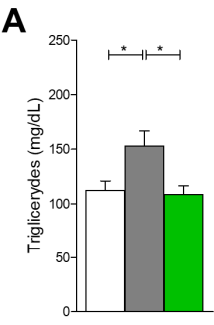

E

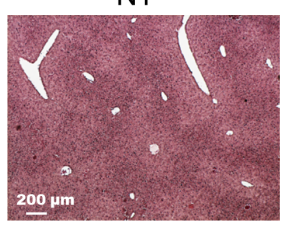

G

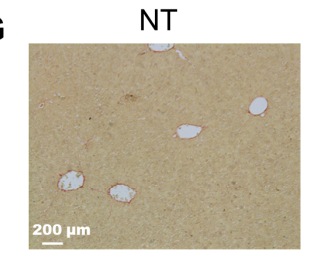

I

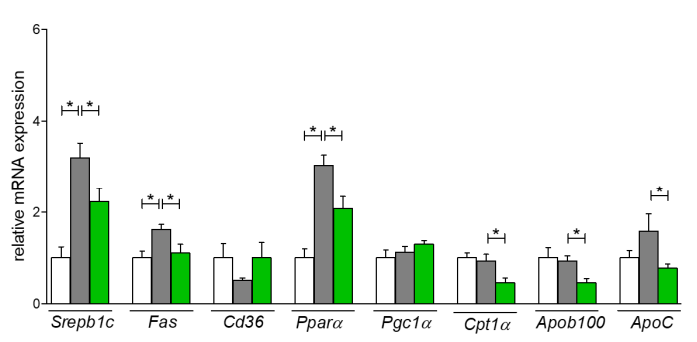

C

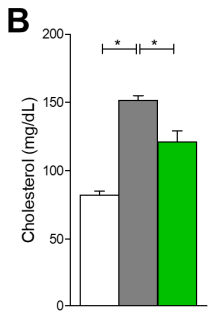

HFD-F

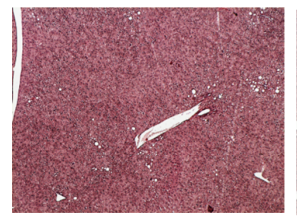

HFD-F

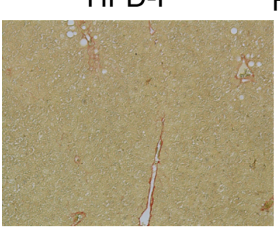

HFD-F + Mt-P 5 mg/kg
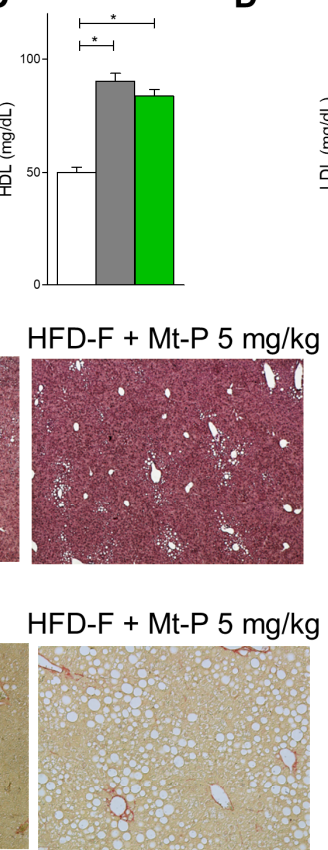

D

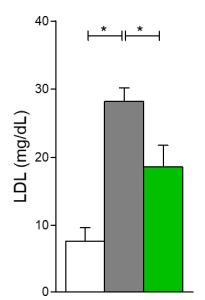

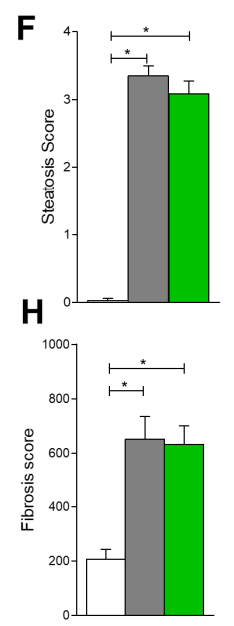

$J$

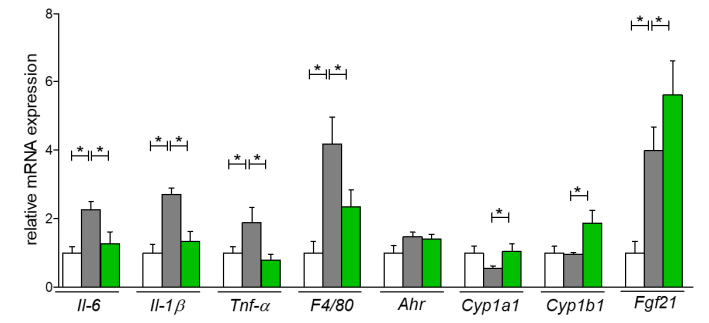

Figure 9. AhR activation exacerbated NASH-like features and fibrosis induced by HFD-F exposure. C57BL/6 male mice were fed a high fat diet (HFD) and fructose or normal chow diet as described before (see Section 2). Serum levels of (A) cholesterol, (B) triglycerides, (C) high density lipoproteins (HDLs), and (D) low density lipoproteins (LDLs). Biochemistry values were measured at the end of the study. (E) Hematoxylin and eosin (H\&E) staining of liver tissues obtained at the end of the study (Magnification $4 \times$ ). NASH severity was scored by assessing the (F) steatosis (NAS) score in at least five different fields per liver in a blind manner. (G) Sirius red staining of liver tissues obtained at the end of the study (Magnification 10×). (H) Liver fibrosis score (\% collagen deposition) was measured, as described in Material and Methods, by ImageJ analysis. The images shown in panels (E-H) are representative of at least 10 others, each one obtained from an individual mouse, showing a similar pattern of regulation. Hepatic expression of (I) genes involved in the regulation of lipid synthesis (Srebp1c, Fas), fatty acids oxidation (Ppar $\alpha, P g c 1 \alpha, C p t 1 \alpha)$, and very low-density lipoprotein (VLDL)

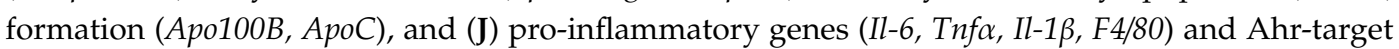
genes (Ahr, Cyp1a1, Cyp1b1, Fgf21). Values are normalized relative to Gapdh mRNA and are expressed as mean \pm SEM of six/ten mice per group (NT $=6$; HFD-F $=8 ; \mathrm{HFD}-\mathrm{F}+\mathrm{Mt}-\mathrm{P} 5 \mathrm{mg} / \mathrm{kg}=10)\left({ }^{*} p<0.05\right)$. 
A

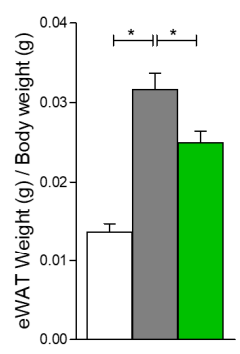

B

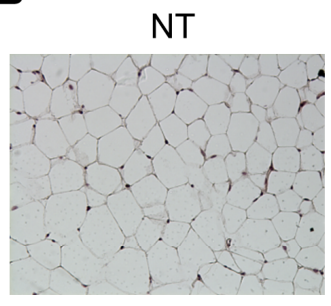

HFD-F + Mt-P 5 mg/kg

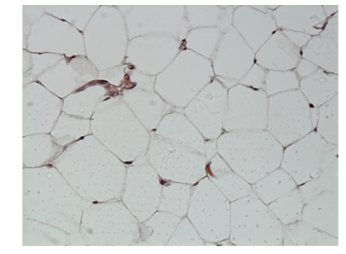

C

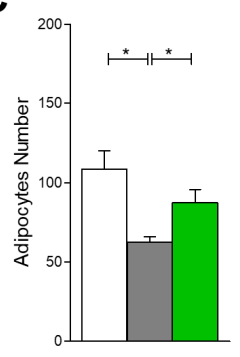

D

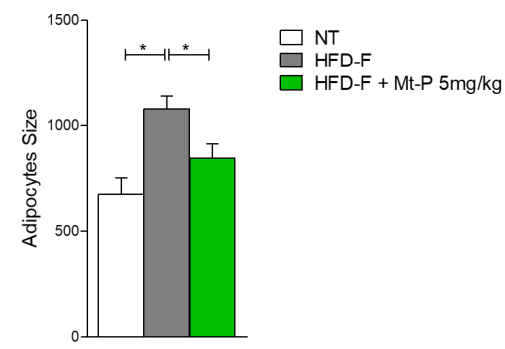

$\mathbf{E}$

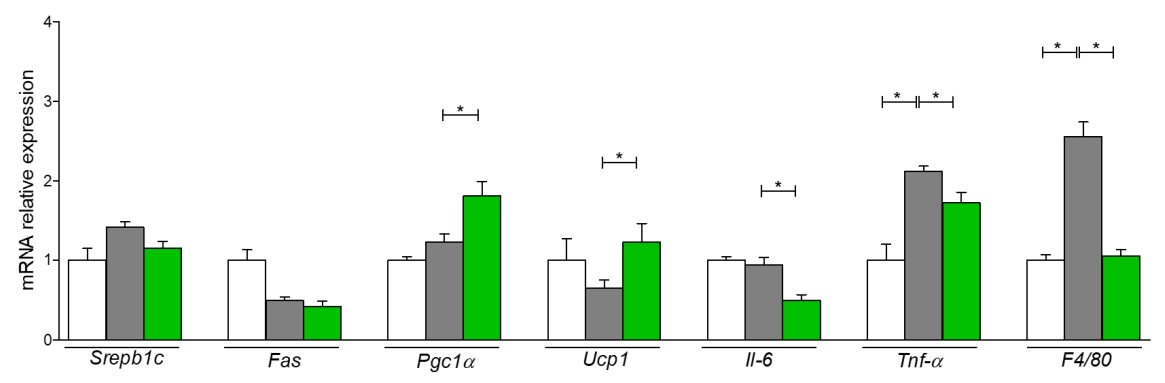

F

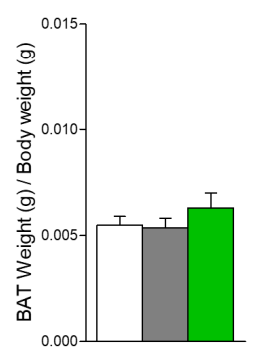

Figure 10. Effects of AhR activation in extrahepatic tissues. C57BL/6 male mice were fed a high fat diet (HFD) and fructose or normal chow diet as described before (see Section 2). (A-C): Results in epididymal white adipose tissue (eWAT). (A) Ratio eWAT weight/body weight. (B) Hematoxylin and eosin (H\&E) staining of white adipose tissue sections obtained at the end of the study. The images shown are representative of at least 10 others, each one obtained from an individual mouse, showing a similar pattern of regulation (magnification $4 \times$ ). (C) Adipocytes number and (D) size obtained from analysis of H\&E staining performed with ImageJ. (E) Changes in mRNA expression of eWAT genes. (F) Ratio brown adipose tissue (BAT) weight/body weight. Values are normalized relative to Gapdh $\mathrm{mRNA}$ and are expressed as mean $\pm \mathrm{SEM}$ of six/ten mice per group (NT $=6$; HFD-F $=8$; HFD-F + Mt-P $5 \mathrm{mg} / \mathrm{kg}=10)\left({ }^{*} p<0.05\right)$. 
Co-treating mice with the Mt-P reversed this pattern-i.e., reduced eWAT weight (as illustrated in Figure 10A) and restored adipocyte morphology (Figure 10B-D, ${ }^{*} p<0.05$ ). Because obesity is associated with an increase in macrophage infiltration in WAT, we then measured the expression of pro-inflammatory markers in eWAT. As shown in Figure 10E, while feeding a HFD-F increased expression of $F 4 / 80$ and Tnf- $\alpha$, this pattern was reversed by Mt-P (Figure 10E, ${ }^{*} p<0.05$ ). Finally, treating HFD-F mice with Mt-P resulted in an increased expression of $\operatorname{Pgc1} \alpha$ and $U c p 1$, two genes that were associated with a significant increase in fatty acid oxidation rate (Figure $10 \mathrm{E},{ }^{*} p<0.05$ ).

As shown in Figure S4, feeding mice with a HFD-F resulted in profound alteration of bile acid pool, marked by a severe reduction of Tauro-cholic acid (T-CA). In contrast, the content of other primary bile acids such as Tauro- $\beta$ muricholic acid (T- $\beta$ MCA) were markedly increased in response to HFD-F exposure (Figure S4A). This bile acid pattern suggests an inhibition of FXR signaling, because T-CA is the predominant FXR agonist in mice, and T- $\beta$ MCA functions as an FXR antagonist [36]. Treating mice with Mt-P did not reverse this pattern, thus revealing that AhR activation resulted in an FXR antagonism (Figure S4A). These data were confirmed also by the analysis of expression of Shp and Cyp7a1 genes (Figure S4B, ${ }^{\#} p<0.05$ versus naïve mice, ${ }^{*} p<0.05$ versus HFD-F mice).

As shown in Figures S5 and S6, the beneficial effects exerted by Mt-P on body weight and glucose metabolism and biochemistry were completely abrogated by AhR gene ablation.

\section{Discussion}

Similarly, to other flavonoids, pelargonidins have been used in traditional medicine in the treatment of a number of human alignments [37]. However, because of their poor systemic bioavailability and unpredictable pharmacokinetic, their clinical efficacy remains controversial [20,38-44].

In the present study, we report the chemical synthesis and pharmacological characterization of a methylated derivative of pelargonidin (Mt-P). By using in vitro and in vivo approaches, we have shown that this agent binds and activates the AhR, a nuclear receptor widely expressed in the intestine, liver, and metabolic tissues. Results of transactivation experiments carried out in AhR-overexpressing HepG2 cells demonstrate that Mt-P transactivates the AhR at an $\mathrm{EC}_{50}$ of $\sim 2 \mu \mathrm{M}$, and was $\sim 2$-fold more potent than the natural compound. The synthetic agent was also significantly more effective than the parent compound in modulating effector functions elicited by exposure of macrophage cell line or freshly isolated macrophages to LPS/IFN $\gamma$. In this in vitro setting, in contrast to the natural pelargonidin, Mt-P inhibited Il-1 $\beta$, Tnf $\alpha$, and Il-6 genes transcription in an AhR-dependent manner. Moreover, while Mt-P significantly increased the production of $\operatorname{Tgf} \beta$ and Il-10, two signature cytokines for M2-polarized macrophages, the natural compound was only partially effective in increasing the Il-10 gene expression. These regulatory effects, were at least partially due a direct regulation of gene transcription. Indeed, data obtained in vitro in RAW264.7 cells, a macrophage cell line, by a ChIP assay demonstrate that exposure to Mt-P increases the binding of AhR/ARNT dimer on the promoter of its target gene, Cyp1a1 [45]. Taken together, these data highlight that the Mt-P is a robust AhR ligand in vitro [46], and AhR gene ablation abrogates the anti-inflammatory activities of Mt-P in these settings.

Based on these in vitro findings, we then sought confirmation of whether the Mt-P effectively modulates macrophages and $\mathrm{T}$ cell polarization in vivo in a mouse model of intestinal inflammation. The model of colitis induced by intra-rectal administration of TNBS is a Th1-mediated mouse model of colitis that shows similarities with immune dysfunctions found in Crohn's disease patients. In this model, treating TNBS mice with Mt-P dose-dependently rescued from development of colitis in an AhR-dependent manner. A dose of $5 \mathrm{mg} / \mathrm{kg} /$ day of Mt-P fully prevented the development of "clinical" signs and symptoms of colitis, as measured by assessment of CDAI, body weight changes, colon length, and histopathologic changes, and reversed inflammation and immune dysfunction. These effects were AhR-dependent and abrogated by AhR gene ablation. Thus, not only did $\mathrm{AhR}^{-/-}$mice develop a severe disease resulting in a four-day mortality of $\sim 80 \%$, but Mt-P failed to rescue from disease development in these animals. These in vivo beneficial effects were supported by a robust down-regulation of the levels of colon expression of pro-inflammatory cytokines (Il-1 $\beta, I l-6$, Tnf- $\alpha$ and 
Ifn- $Y$ mRNA), while increased the levels of Tgf $\beta$ and Il-10 genes, two anti-inflammatory cytokines. Consistent with these data, the phenotypic characterization by flow cytometry analysis of immune cells isolated from colonic lamina propria demonstrates that treating colitic mice with Mt-P not only reduced the amount of pro-inflammatory cells, but increased the number of $\mathrm{CD}^{+} \mathrm{FoxP}^{+}$cells, i.e., Treg cells, as well as CD11+GR-IL-10+, i.e., M2 macrophages. Together these findings support the notion that Mt-P activates the AhR in intestinal immune cells, inhibiting the skew toward M1 and Th1 responses by altering the production of pro-inflammatory mediators and promoting the development of M2, tolerogenic, macrophages, and Treg cells. In addition to a direct modulation of intestinal immunity, Mt-P increased the intestinal expression of AhR and its target genes, Cyp1a1 and Cyp1b1, in this model. Furthermore, Mt-P effectively promoted migration and survival of intestinal epithelial cells in vitro, suggesting that $\mathrm{AhR}$ activation by Mt-P could contribute to the maintenance of healthy state of the intestinal barrier [47].

Because maintenance of intestinal homeostasis is increasingly recognized as an important therapeutic target in obesity and NASH, we then investigated whether Mt-P was beneficial in a rodent model of diet-induced NASH. NASH is a highly prevalent human disorder associated with metabolic syndrome and sub-clinical inflammation, for which therapy remains suboptimal [14,46-49]. Results shown in Figures 8-10 and supplementary Figures S4-S6 demonstrate that treating mice with Mt-P at the dose of $5 \mathrm{mg} / \mathrm{kg} /$ day effectively protected from body weight gain, development of insulin resistance, and metabolic dysfunction caused by HFD-F. These beneficial effects were abrogated by AhR gene ablation, supporting the concept that AhR activation by Mt-P was the main mechanism underling the pharmacological effects of the pelargonidin derivative in this model.

In addition to attenuation of body weight gain, treating mice with Mt-P effectively improved serum biochemistry, and reduced triglycerides, cholesterol plasma levels, and LDL-C, while levels of HDL-C remained unchanged. Analysis of the liver transcriptoma demonstrated that treating mice with Mt-P redirected the expression of several genes involved in lipid metabolism, including Srebp1c and Fasn, a gene that encodes for the fatty acid synthase, a rate-limiting enzyme involved in fatty acid synthesis. Thus, while feeding mice a HFD increased liver lipid biosynthesis, this effect was reversed by AhR activation. However, in contrast to the beneficial effects exerted on plasma biochemistry, treatment of HFD-F mice with Mt-P worsened liver histopathology, resulting in dramatic exacerbation of hepatocytes ballooning. These findings are consistent with a previous study showing that activation of AhR dissociated fatty liver metabolism from insulin resistance by inducing FGF-21. Accordingly, it has been shown that while AhR transgenic mice were protected from HFD-induced obesity and insulin resistance, they developed severe hepato-steatosis. This finding suggests that, at least in mice, systemic AhR activation can dissociate the severity of liver steatosis from insulin sensitivity, and that intake of natural AhR ligand should be carefully evaluated in NASH patients.

Previous studies have demonstrated that AhR activation in the liver induces the expression of FGF-21. It is known that FGF21 exerts multiple metabolic effects, including attenuation of body weight gain and insulin resistance [50]. FGF-21 is almost exclusively produced by the liver and acts on hepatocytes in an endocrine or paracrine fashion by binding to FGF receptor 4, which uses the protein $\beta$-klotho as a co-receptor. Because treatment of obese mice with FGF21 leads to weight loss and increased energy expenditure through the activation of eWAT or BAT [51,52], it is likely that FGF-21 mRNA up-regulation in the liver might explain some of the beneficial effects exerted by Mt-P. Importantly, FGF-21 is a direct transcriptional target of AhR, and AhR/ARNT binding sites have been identified in the FGF-21 promoter; although, these AHR-RE overlap binding sequences for peroxisome proliferator-activated receptor $\alpha$ (PPAR $\alpha)$, carbohydrate response element-binding protein (ChREBP), and cAMP response element-binding protein hepatocyte specific (CREBH), which also regulate FGF21 gene transcription in hepatocytes [53]. 
Despite Mt-P-attenuated body weight gain, this agent promoted liver lipid accumulation. Several changes caused by Mt-P might explain this effect. First of all, Mt-P treatment resulted in an AhR-dependent regulation of the expression of Cd36, a gene encoding for the hepatic fatty acid translocase, a membrane transporter involved in the "reverse" cholesterol transport [54]. CD36 binds long-chain fatty acids and facilitates their transport into cells, contributing to the pathogenesis of metabolic disorders such as diabetes and obesity [55]. CD36 is, quantitatively, the most important scavenger receptor for uptake of oxidized lipoproteins by hepatocytes, and previous studies have shown that its upregulation is associated with insulin resistance, hyper-insulinemia, and increased steatosis in patients with NASH. Thus, its up-regulation is consistent with an enhanced FFA uptake by hepatocytes. In addition to an enhanced uptake of circulating lipids by hepatocytes, treating HFD-F mice with Mt-P caused a dramatic down-regulation of Apob100 and ApoC, two genes involved in lipoprotein assembly. Apob100 is the primary liver apolipoprotein and is the carrier for chylomicrons, low-density lipoprotein (LDL), very low-density lipoprotein (VLDL), and intermediate density lipoprotein (IDL), while it is not found in HDL. Because ApoB-100 is necessary for assembly and secretion of VLDL by the liver, and might also serve as the primary ligand for LDL receptor medicated clearance of LDL particles from the blood, our data suggest that accumulation of liver lipids in response to AhR activation might result from a decreased lipid secretion due to an ApoB100-dependent impairment of VLDL formation and secretion by hepatocytes [56]. Liver steatosis deterioration was not due to inflammation, since AhR activation by Mt-P resulted in a robust attenuation in the expression of inflammatory biomarkers in the intestine, liver, and eWAT, confirming that activation of the Mt-P/AhR pathway drives anti-inflammatory signaling. Since HFD-related gut barrier dysfunction is a source of gut, WAT and liver inflammation, and insulin resistance [57], and AhR exerts beneficial effects on the intactness of the gut epithelial barrier [1], attenuation of epithelial barrier dysfunction caused by Mt-P in this model might contribute to the beneficial effects on insulin sensitivity.

In conclusion, we have reported the development of a synthetic derivative of pelargonidin, Mt-P, that activates the AhR and exerts robust anti-inflammatory activity in vitro and in vivo in a AhR-dependent manner. Long-term administration of Mt-P in the setting of mice fed a HFD-F ameliorates insulin sensitivity and attenuates body weight gain, but worsens VLDL biosynthesis and secretion by hepatocytes. The study demonstrates the utility of harnessing nutraceuticals to develop novel pharmacological agents, but also highlights the potential side effects of poorly-investigated nutraceuticals.

Supplementary Materials: The following are available online at http://www.mdpi.com/2072-6643/11/8/1820/s1. Figure S1: In vitro selectivity of P and Mt-P. Figure S2: P and Mt-P reducing the severity of colitis in a dose dependent manner. Figure S3: Comparison of the beneficial effect of Mt-P and dexamethasone in a mouse model of colitis. Figure S4: Gallbladder bile acids composition. Figure S5: Effects of HFD-F on Ahr--- mice. Figure S6: Analisys of HFD-F model in hepatic and extrahepatic tissues on $\mathrm{Ahr}^{-/-}$mice.

Author Contributions: S.F. and G.C. conceived the study; M.B. (Michele Biagioli), C.F., M.B. (Martina Bordoni), C.D.G. and F.C. carried out animal studies; A.C., S.M., and R.R. performed in vitro studies and molecular analyses; G.C. and G.A. carried out chemical processes of extraction and synthesis; A.B. and A.F. performed docking studies and LC-HRMS analyses; A.C., M.B. (Michele Biagioli) , C.F., and S.M. performed data analysis; M.B. (Michele Biagioli), S.F., A.C., E.D., M.B. (Monia Baldoni) , and P.R. wrote the manuscript; all authors read and approved the final version of the manuscript.

Funding: This research received no external funding.

Conflicts of Interest: The authors declare that the research was conducted in the absence of any commercial or financial relationship that could be construed as a potential conflict of interest. 


$\begin{array}{ll}\text { Abbreviations } \\ \text { AhR } & \text { aryl hydrocarbon receptor } \\ \text { ARNT } & \text { AhR nuclear translocator } \\ \text { Hsp90 } & \text { heat shock protein } 90 \\ \text { XREs } & \text { xenobiotic response elements } \\ \text { P } & \text { pelargonidin } \\ \text { Mt-P } & \text { methylated pelargonidin } \\ \text { IBD } & \text { inflammatory bowel disease } \\ \text { NASH } & \text { non-alcoholic steato-hepatitis } \\ \text { HFD-F } & \text { high fat diet and fructose } \\ \text { WAT } & \text { white adipose tissue } \\ \text { BAT } & \text { brown adipose tissue } \\ \text { eWAT } & \text { epididymal adipose tissue } \\ \text { OGTT } & \text { oral glucose tolerance test } \\ \text { BMI } & \text { body mass index } \\ \text { LDL } & \text { low density lipoproteins } \\ \text { HDL } & \text { high density lipoproteins } \\ \text { H\&E } & \text { Hematoxilin and Eosin } \\ \text { T-CA } & \text { Tauro-cholic acid } \\ \text { T- } \beta \text { MCA } & \text { Tauro- } \beta \text { muricholic acid }\end{array}$

\section{References}

1. Lamas, B.; Natividad, J.M.; Sokol, H. Aryl hydrocarbon receptor and intestinal immunity. Mucosal Immunol. 2018, 11, 1024-1038. [CrossRef]

2. Denison, M.S.; Soshilov, A.A.; He, G.; DeGroot, D.E.; Zhao, B. Exactly the Same but Different: Promiscuity and Diversity in the Molecular Mechanisms of Action of the Aryl Hydrocarbon (Dioxin) Receptor. Toxicol. Sci. 2011, 124, 1-22. [CrossRef]

3. Stevens, E.A.; Mezrich, J.D.; Bradfield, C.A. The aryl hydrocarbon receptor: A perspective on potential roles in the immune system. Immunology 2009, 127, 299-311. [CrossRef] [PubMed]

4. Zhou, L. AHR Function in Lymphocytes: Emerging Concepts. Trends Immunol. 2016, 37, 17-31. [CrossRef] [PubMed]

5. Gandhi, R.; Kumar, D.; Burns, E.J.; Nadeau, M.; Dake, B.; Laroni, A.; Kozoriz, D.; Weiner, H.L.; Quintana, F.J. Activation of the aryl hydrocarbon receptor induces human type 1 regulatory T cell-like and Foxp3(+) regulatory T cells. Nat. Immunol. 2010, 11, 846-853. [CrossRef]

6. Qiu, J.; Guo, X.; Chen, Z.-M.E.; He, L.; Sonnenberg, G.F.; Artis, D.; Fu, Y.-X.; Zhou, L. Group 3 Innate Lymphoid Cells Inhibit T-Cell-Mediated Intestinal Inflammation through Aryl Hydrocarbon Receptor Signaling and Regulation of Microflora. Immunity 2013, 39, 386-399. [CrossRef] [PubMed]

7. Monteleone, I.; Rizzo, A.; Sarra, M.; Sica, G.; Sileri, P.; Biancone, L.; Macdonald, T.T.; Pallone, F.; Monteleone, G. Aryl Hydrocarbon Receptor-Induced Signals Up-regulate IL-22 Production and Inhibit Inflammation in the Gastrointestinal Tract. Gastroenterology 2011, 141, 237-248. [CrossRef]

8. Arsenescu, R.; Arsenescu, V.; Zhong, J.; Nasser, M.; Melinte, R.; Dingle, R.; Swanson, H.; de Villiers, W.J. Role of the xenobiotic receptor in inflammatory bowel disease. Inflamm. Bowel Dis. 2011, 17, 1149-1162. [CrossRef]

9. Kiss, E.A.; Vonarbourg, C.; Kopfmann, S.; Hobeika, E.; Finke, D.; Esser, C.; Diefenbach, A. Natural Aryl Hydrocarbon Receptor Ligands Control Organogenesis of Intestinal Lymphoid Follicles. Science 2011, 334, 1561-1565. [CrossRef]

10. Lee, J.S.; Cella, M.; McDonald, K.G.; Garlanda, C.; Kennedy, G.D.; Nukaya, M.; Mantovani, A.; Kopan, R.; Bradfield, C.A.; Newberry, R.D.; et al. AHR drives the development of gut ILC22 cells and postnatal lymphoid tissues via pathways dependent on and independent of Notch. Nat. Immunol. 2011, 13, 144-151. [CrossRef] 
11. Li, Y.; Innocentin, S.; Withers, D.R.; Roberts, N.A.; Gallagher, A.R.; Grigorieva, E.F.; Wilhelm, C.; Veldhoen, M. Exogenous Stimuli Maintain Intraepithelial Lymphocytes via Aryl Hydrocarbon Receptor Activation. Cell 2011, 147, 629-640. [CrossRef] [PubMed]

12. Luther, J.; Garber, J.J.; Khalili, H.; Dave, M.; Bale, S.S.; Jindal, R.; Motola, D.L.; Luther, S.; Bohr, S.; Jeoung, S.W.; et al. Hepatic Injury in Nonalcoholic Steatohepatitis Contributes to Altered Intestinal Permeability. Cell. Mol. Gastroenterol. Hepatol. 2015, 1, 222-232. [CrossRef] [PubMed]

13. Miele, L.; Valenza, V.; la Torre, G.; Montalto, M.; Cammarota, G.; Ricci, R.; Mascianà, R.; Forgione, A.; Gabrieli, M.L.; Perotti, G. Increased intestinal permeability and tight junction alterations in nonalcoholic fatty liver disease. Hepatology 2009, 49, 1877-1887. [CrossRef] [PubMed]

14. Fiorucci, S.; Biagioli, M.; Distrutti, E. Future trends in the treatment of non-alcoholic steatohepatitis. Pharmacol. Res. 2018, 134, 289-298. [CrossRef] [PubMed]

15. Biedermann, L.; Mwinyi, J.; Scharl, M.; Frei, P.; Zeitz, J.; Kullak-Ublick, G.A.; Vavricka, S.R.; Fried, M.; Weber, A.; Humpf, H.-U.; et al. Bilberry ingestion improves disease activity in mild to moderate ulcerative colitis-An open pilot study. J. Crohns Colitis 2013, 7, 271-279. [CrossRef] [PubMed]

16. García-Conesa, M.-T.; Chambers, K.; Combet, E.; Pinto, P.; Garcia-Aloy, M.; Andrés-Lacueva, C.; De Pascual-Teresa, S.; Mena, P.; Ristic, A.K.; Hollands, W.J.; et al. Meta-Analysis of the Effects of Foods and Derived Products Containing Ellagitannins and Anthocyanins on Cardiometabolic Biomarkers: Analysis of Factors Influencing Variability of the Individual Responses. Int. J. Mol. Sci. 2018, 19, 694. [CrossRef] [PubMed]

17. Mazza, G. Compositional and Functional Properties of Saskatoon Berry and Blueberry. Int. J. Fruit Sci. 2005, 5, 101-120. [CrossRef]

18. Jennings, A.; Welch, A.A.; Fairweather-Tait, S.J.; Kay, C.; Minihane, A.-M.; Chowienczyk, P.; Jiang, B.; Cecelja, M.; Spector, T.; MacGregor, A.; et al. Higher anthocyanin intake is associated with lower arterial stiffness and central blood pressure in women. Am. J. Clin. Nutr. 2012, 96, 781-788. [CrossRef]

19. Pervin, M.; Hasnat, M.A.; Lim, J.-H.; Lee, Y.-M.; Kim, E.O.; Um, B.-H.; Lim, B.O. Preventive and therapeutic effects of blueberry (Vaccinium corymbosum) extract against DSS-induced ulcerative colitis by regulation of antioxidant and inflammatory mediators. J. Nutr. Biochem. 2016, 28, 103-113. [CrossRef]

20. Roth, S.; Spalinger, M.R.; Gottier, C.; Biedermann, L.; Zeitz, J.; Lang, S.; Weber, A.; Rogler, G.; Scharl, M. Bilberry-Derived Anthocyanins Modulate Cytokine Expression in the Intestine of Patients with Ulcerative Colitis. PLoS ONE 2016, 11, e0154817. [CrossRef]

21. Revilla, E.; Ryan, J.-M.; Martín-Ortega, G. Comparison of Several Procedures Used for the Extraction of Anthocyanins from Red Grapes. J. Agric. Food Chem. 1998, 46, 4592-4597. [CrossRef]

22. Cruz, L.; Mateus, N.; De Freitas, V. First chemical synthesis report of an anthocyanin metabolite with in vivo occurrence: Cyanidin-4'-O-methyl-3-glucoside. Tetrahedron Lett. 2013, 54, 2865-2869. [CrossRef]

23. Sali, A.; Blundell, T.L. Comparative Protein Modelling by Satisfaction of Spatial Restraints. J. Mol. Boil. 1993, 234, 779-815. [CrossRef] [PubMed]

24. Biagioli, M.; Carino, A.; Cipriani, S.; Francisci, D.; Marchianò, S.; Scarpelli, P.; Sorcini, D.; Zampella, A.; Fiorucci, S. The Bile Acid Receptor GPBAR1 Regulates the M1/M2 Phenotype of Intestinal Macrophages and Activation of GPBAR1 Rescues Mice from Murine Colitis. J. Immunol. 2017, 199, 718-733. [CrossRef] [PubMed]

25. Frohlich, J.R.; Alarcón, C.N.; Toarmino, C.R.; Sunseri, A.K.; Hockman, T.M. Comparison of Serial Blood Collection by Facial Vein and Retrobulbar Methods in C57BL/6 Mice. J. Am. Assoc. Lab. Anim. Sci. 2018, 57, 382-391. [CrossRef] [PubMed]

26. Carino, A.; Marchianò, S.; Biagioli, M.; Bucci, M.; Vellecco, V.; Brancaleone, V.; Fiorucci, C.; Zampella, A.; Monti, M.C.; Distrutti, E.; et al. Agonism for the bile acid receptor GPBAR1 reverses liver and vascular damage in a mouse model of steatohepatitis. FASEB J. 2018, 33, 2809-2822. [CrossRef] [PubMed]

27. Carino, A.; Cipriani, S.; Marchianò, S.; Biagioli, M.; Santorelli, C.; Donini, A.; Zampella, A.; Monti, M.C.; Fiorucci, S. BAR502, a dual FXR and GPBAR1 agonist, promotes browning of white adipose tissue and reverses liver steatosis and fibrosis. Sci. Rep. 2017, 7, 42801. [CrossRef] [PubMed]

28. Renga, B.; Bucci, M.; Cipriani, S.; Carino, A.; Monti, M.C.; Zampella, A.; Gargiulo, A.; d'Emmanuele di Villa Bianca, R.; Distrutti, E.; Fiorucci, S. Cystathionine $\gamma$-lyase, a H2S-generating enzyme, is a GPBAR1-regulated gene and contributes to vasodilation caused by secondary bile acids. Am. J. Physiol. Heart Circ. Physiol. 2015, 309, H114-H126. [CrossRef] 
29. Fiorucci, S.; Antonelli, E.; Rizzo, G.; Renga, B.; Mencarelli, A.; Riccardi, L.; Orlandi, S.; Pellicciari, R.; Morelli, A. The nuclear receptor SHP mediates inhibition of hepatic stellate cells by FXR and protects against liver fibrosis. Gastroenterology 2004, 127, 1497-1512. [CrossRef]

30. Carino, A.; Cipriani, S.; Marchianò, S.; Biagioli, M.; Scarpelli, P.; Zampella, A.; Monti, M.C.; Fiorucci, S. Gpbar1 agonism promotes a Pgc-1 $\alpha$-dependent browning of white adipose tissue and energy expenditure and reverses diet-induced steatohepatitis in mice. Sci. Rep. 2017, 7, 13689. [CrossRef]

31. Fraccalvieri, D.; Soshilov, A.A.; Karchner, S.I.; Franks, D.G.; Pandini, A.; Bonati, L.; Hahn, M.E.; Denison, M.S. Comparative analysis of homology models of the AH receptor ligand binding domain: Verification of structure-function predictions by site-directed mutagenesis of a nonfunctional receptor. Biochemistry 2013, 52, 714-725. [CrossRef] [PubMed]

32. Perkins, A.; Phillips, J.L.; Kerkvliet, N.I.; Tanguay, R.L.; Perdew, G.H.; Kolluri, S.K.; Bisson, W.H. A Structural Switch between Agonist and Antagonist Bound Conformations for a Ligand-Optimized Model of the Human Aryl Hydrocarbon Receptor Ligand Binding Domain. Biology 2014, 3, 645-669. [CrossRef] [PubMed]

33. Daumke, O.; Schulte, K. Structural basis for aryl hydrocarbon receptor mediated gene activation. Structure 2017, 25, 1025-1033.

34. Soshilov, A.A.; Denison, M.S. Ligand Promiscuity of Aryl Hydrocarbon Receptor Agonists and Antagonists Revealed by Site-Directed Mutagenesis. Mol. Cell. Boil. 2014, 34, 1707-1719. [CrossRef] [PubMed]

35. Lanis, J.M.; Alexeev, E.E.; Curtis, V.F.; Kitzenberg, D.A.; Kao, D.J.; Battista, K.D.; Gerich, M.E.; Glover, L.E.; Kominsky, D.J.; Colgan, S.P. Tryptophan Metabolite Activation of the Aryl Hydrocarbon Receptor Regulates IL10 Receptor Expression on Intestinal Epithelia. Mucosal Immunol. 2017, 10, 1133-1144. [CrossRef] [PubMed]

36. La Frano, M.R.; Hernandez-Carretero, A.; Weber, N.; Borkowski, K.; Pedersen, T.L.; Osborn, O.; Newman, J.W. Diet-induced obesity and weight loss alter bile acid concentrations and bile acid-sensitive gene expression in insulin target tissues of C57BL/6J mice. Nutr. Res. 2017, 46, 11-21. [CrossRef] [PubMed]

37. Venkatakrishnan, K.; Chiu, H.-F.; Wang, C.K. Extensive review of popular functional foods and nutraceuticals against obesity and its related complications with a special focus on randomized clinical trials. Food Funct. 2019, 10, 2313-2329. [CrossRef] [PubMed]

38. Cassidy, A.; Rogers, G.; Peterson, J.J.; Dwyer, J.T.; Lin, H.; Jacques, P.F. Higher dietary anthocyanin and flavonol intakes are associated with anti-inflammatory effects in a population of US adults1. Am. J. Clin. Nutr. 2015, 102, 172-181. [CrossRef] [PubMed]

39. David, L.A.; Maurice, C.F.; Carmody, R.N.; Gootenberg, D.B.; Button, J.E.; Wolfe, B.E.; Ling, A.V.; Devlin, A.S.; Varma, Y.; Fischbach, M.A.; et al. Diet rapidly and reproducibly alters the human gut microbiome. Nature 2014, 505, 559-563. [CrossRef]

40. Farzaei, M.H.; Rahimi, R.; Abdollahi, M. The role of dietary polyphenols in the management of inflammatory bowel disease. Curr. Pharm. Biotechnol. 2015, 16, 196-210. [CrossRef]

41. He, J.; Giusti, M.M. Anthocyanins: Natural Colorants with Health-Promoting Properties. Annu. Rev. Food Sci. Technol. 2010, 1, 163-187. [CrossRef] [PubMed]

42. Pereira, S.R.; Figueiredo, I.; Freitas, V.; Dinis, T.C.P.; Almeida, L.M. Comparison of anti-inflammatory activities of an anthocyanin-rich fraction from Portuguese blueberries (Vaccinium corymbosum L.) and 5-aminosalicylic acid in a TNBS-induced colitis rat model. PLoS ONE 2017, 12, e0174116. [CrossRef] [PubMed]

43. Pojer, E.; Mattivi, F.; Johnson, D.; Stockley, C.S. The Case for Anthocyanin Consumption to Promote Human Health: A Review. Compr. Rev. Food Sci. Food Saf. 2013, 12, 483-508. [CrossRef]

44. Vezza, T.; Rodríguez-Nogales, A.; Algieri, F.; Utrilla, M.P.; Rodriguez-Cabezas, M.E.; Galvez, J. Flavonoids in Inflammatory Bowel Disease: A Review. Nutrients 2016, 8, 211. [CrossRef] [PubMed]

45. Kamenickova, A.; Anzenbacherová, E.; Pavek, P.; Soshilov, A.A.; Denison, M.S.; Anzenbacher, P.; Dvorak, Z. Pelargonidin activates the AhR and induces CYP1A1 in primary human hepatocytes and human cancer cell lines HepG2 and LS174T. Toxicol. Lett. 2013, 218, 253-259. [CrossRef] [PubMed]

46. Esser, C.; Rannug, A.; Stockinger, B. The aryl hydrocarbon receptor in immunity. Trends Immunol. 2009, 30, 447-454. [CrossRef]

47. Nunes, C.; Teixeira, N.; Serra, D.; Freitas, V.; Almeida, L.; Laranjinha, J. Red wine polyphenol extract efficiently protects intestinal epithelial cells from inflammation via opposite modulation of JAK/STAT and Nrf2 pathways. Toxicol. Res. 2016, 5, 53-65. [CrossRef] 
48. Lin, Y.H.; Luck, H.; Khan, S.; Schneeberger, P.H.H.; Tsai, S.; Clemente-Casares, X.; Lei, H.; Leu, Y.L.; Chan, Y.T.; Chen, H.Y.; et al. Aryl hydrocarbon receptor agonist indigo protects against obesity-related insulin resistance through modulation of intestinal and metabolic tissue immunity. Int. J. Obes. Lond. 2019. [CrossRef]

49. Natividad, J.M.; Agus, A.; Planchais, J.; Lamas, B.; Jarry, A.C.; Martin, R.; Michel, M.-L.; Chong-Nguyen, C.; Roussel, R.; Straube, M.; et al. Impaired Aryl Hydrocarbon Receptor Ligand Production by the Gut Microbiota Is a Key Factor in Metabolic Syndrome. Cell Metab. 2018, 28, 737-749. [CrossRef]

50. Staiger, H.; Keuper, M.; Berti, L.; Hrabe de Angelis, M.; Häring, H.U. Fibroblast Growth Factor 21-Metabolic Role in Mice and Men. Endocr. Rev. 2017, 38, 468-488. [CrossRef]

51. Fisher, F.M.; Kleiner, S.; Douris, N.; Fox, E.C.; Mepani, R.J.; Verdeguer, F.; Wu, J.; Kharitonenkov, A.; Flier, J.S.; Maratos-Flier, E.; et al. FGF21 regulates PGC-1 $\alpha$ and browning of white adipose tissues in adaptive thermogenesis. Genes Dev. 2012, 26, 271-281. [CrossRef] [PubMed]

52. Fisher, F.M.; Maratos-Flier, E. Understanding the Physiology of FGF21. Annu. Rev. Physiol. 2016, 78, $223-241$. [CrossRef] [PubMed]

53. Girer, N.G.; Murray, I.A.; Omiecinski, C.J.; Perdew, G.H. Hepatic Aryl Hydrocarbon Receptor Attenuates Fibroblast Growth Factor 21 Expression. J. Boil. Chem. 2016, 291, 15378-15387. [CrossRef] [PubMed]

54. Silverstein, R.L.; Febbraio, M. CD36, a Scavenger Receptor Involved in Immunity, Metabolism, Angiogenesis, and Behavior. Sci. Signal. 2009, 2, re3. [CrossRef] [PubMed]

55. Liu, M.; Tso, P.; Woods, S.C. Receptor CD36 links a risk-associated allele to obesity and metabolic disorders. J. Boil. Chem. 2018, 293, 13349-13350. [CrossRef] [PubMed]

56. Sirwi, A.; Hussain, M.M. Lipid transfer proteins in the assembly of apoB-containing lipoproteins. J. Lipid Res. 2018, 59, 1094-1102. [CrossRef]

57. Luck, H.; Tsai, S.; Chung, J.; Clemente-Casares, X.; Ghazarian, M.; Revelo, X.S.; Lei, H.; Luk, C.T.; Shi, S.Y.; Surendra, A.; et al. Regulation of Obesity-Related Insulin Resistance with Gut Anti-inflammatory Agents. Cell Metab. 2015, 21, 527-542. [CrossRef] [PubMed]

(C) 2019 by the authors. Licensee MDPI, Basel, Switzerland. This article is an open access article distributed under the terms and conditions of the Creative Commons Attribution (CC BY) license (http://creativecommons.org/licenses/by/4.0/). 